\title{
Entry and Regulation - Evidence from Health Care Professions *
}

\author{
Catherine Schaumans \\ K.U.Leuven
}

\author{
Frank Verboven \\ K.U.Leuven and C.E.P.R.
}

July 2007

\begin{abstract}
Health care professions have been subject to substantial entry and conduct regulation. Most notably, pharmacies frequently receive high regulated markups over wholesale costs, and are protected from additional competition through geographic entry restrictions. We develop an empirical entry model with two specific features: entry by pharmacies may be restricted, and entry decisions of pharmacies and physicians may be strategic complements. We study the case of Belgium, which is representative for many other European countries with geographic entry restrictions. Our estimates imply that the entry restrictions have directly reduced the number of pharmacies by more than $50 \%$, and indirectly reduced the number of physicians by about $7 \%$. Furthermore, a removal of the entry restrictions combined with a reduction in the regulated markups would lead to a large shift in rents to consumers (taxpayers), without necessarily reducing geographic coverage throughout the country. These findings show that the public interest motivation for the current regime has no empirical support.
\end{abstract}

Keywords: Entry, regulation, professional services.

JEL-codes: I11, K21, L10, L43.

*Acknowledgments: We thank Jan Boone, Hans Degryse, Mary Deily, Geert Dhaene, Martin Gaynor, David Genesove, Michael Mazzeo, Erik Schokkaert, Jo Seldeslachts, Hannes Ullrich, Patrick Van Cayseele, Joel Waldfogel, seminar participants at various places and especially the Editor and two referees for helpful comments. We gratefully acknowledge financial support by the Flemish Science Foundation (FWO, Grant G.0089.04) and a K.U.Leuven Onderzoekstoelage (OT).

Contact: Department of Economics, K.U.Leuven, Naamsestraat 69, B-3000 Leuven, Belgium.

catherine.schaumans@econ.kuleuven.be; frank.verboven@econ.kuleuven.be. 


\section{Introduction}

The regulation of liberal professions, such as lawyers, notaries and pharmacies, has been a widespread phenomenon in many countries. It consists of a variety of measures restricting both entry and conduct. While U.S. courts already started to more consistently apply antitrust laws to many professional services after a Supreme Court Decision in 1975 (Wise (2000)), European countries have only recently shown an interest to liberalize professional regulation. ${ }^{1}$

In this paper, we look at pharmacies and physicians in Belgium to shed new light on the effects of entry and conduct regulation. As in many other European countries, both professions are subject to strict conduct regulation through regulated fees or markups and bans on most types of advertising. In addition, the number of pharmacies is restricted on a geographic basis. An establishment act imposes a maximum number of pharmacies per municipality based on population criteria, implying that new pharmacists typically need to buy up existing establishments if they want to operate independently. These regulations have often been motivated to be in the public interest. In particular, the combination of high fixed markups and tight geographic entry restrictions to pharmacies has been defended to ensure a minimum availability of supply in the less profitable regions without inducing excessive entry elsewhere. The private interest view challenges these motivations, arguing that the regulations are anti-competitive and have no beneficial effects to other parties. ${ }^{2}$

To evaluate the public interest motivation of the current regime, we develop an econometric model of entry by two types of professions: pharmacies and physicians (defined as general practitioners). We extend previous free entry models of Bresnahan and Reiss (1991) and Mazzeo (2002), to account for two key features specific to this market. First, entry of pharmacies is not free because of the geographic entry restrictions. In municipalities where the constraint is binding, it is therefore only possible to infer how many firms are still profitable, but not from how many firms onwards entry would become unprofitable. Second, the entry decisions of pharmacies and physicians may be strategic complements, i.e. entry by one type of firm may make entry by the other type more profitable. The entry model can be used to draw inferences about competitive interaction, both within and between the pro-

\footnotetext{
${ }^{1}$ This interest is evident from Paterson et al.'s (2003) extensive report for the European Commission, describing the state of professional regulation in Europe. This report subsequently led to an official Communication, COM (2004) 83, showing the Commission's commitment to liberalize the professions.

${ }^{2}$ Various policy reports have recently been published. In a detailed report, the U.K.'s Office of Fair Trading (2003) concluded that free entry by pharmacies in the U.K. would benefit consumers. The O.E.C.D. (2000) obtained similar conclusions based on the experiences in a larger set of countries. But it also emphasized that a holistic view be taken: simply introducing free entry of pharmacies without any accompanying measures to lower the currently high regulated markups would likely create (or strengthen) excessive entry.
} 
fessions. In addition, it allows us to assess to which extent the geographic entry restrictions on pharmacies have limited the number of firms, either directly the pharmacies or indirectly the physicians because of their strategic interdependence.

We apply the model to a data set for Belgium, which is representative for many other European countries with geographic entry restrictions on pharmacies. The data contain information on the number of pharmacies and physicians per market (town), and the corresponding demographic characteristics in 2001. Regarding competitive interaction, we find that entry into one profession has a positive effect on the profitability of entry into the other profession, suggesting that the entry decisions by firms of different professions are strategic complements. Furthermore, entry does not lead to intensified (non-price) competition among firms of the same profession. Regarding the geographic entry restrictions, we find that they have substantially limited the number of firms. A simple removal of all geographic entry restrictions without any accompanying measures would more than double the number of pharmacies, and also indirectly increase the number of physicians by $7 \%$ due to strategic complementarities. Combining a full removal of the entry restrictions with an absolute reduction in the pharmacies' gross markups by up to 7.5-15\% (down from the current 23\%), would keep the total number of pharmacies in the country constant. Our overall conclusions are that an appropriate combined policy of reduced geographic entry restrictions and reduced regulated markups can lead to a large shift in rents to consumers (tax payers) without necessarily reducing geographic coverage. This strongly indicates that the current regime of high regulated markups and restricted entry protects the private interests of pharmacies rather than the public interest.

There is a small related empirical literature on free entry and social inefficiency. Berry and Waldfogel (1999) show how free entry of radio stations can be inefficient in an imperfectly competitive market. Hsieh and Moretti (2003) look at real estate agents, and document the inefficiency of free entry in a market with fixed regulated markups. ${ }^{3}$ In contrast to these studies, we concentrate on a case of restricted entry. In principle, given that markups are regulated at a distortionary high level, it may be socially desirable to introduce a second distortion and restrict entry. However, our analysis shows how a properly combined policy of loosening the entry restrictions and lowering the markups may lead to large shifts in rents from pharmacies to consumers (tax payers) without reducing the availability of supply. In the concluding section, we come back to the question whether these shifts in rents are beneficial.

Our analysis also relates to empirical work on vertical restraints. Lafontaine and Slade

\footnotetext{
${ }^{3}$ For a theoretical analysis of the conditions under which free entry may be socially inefficient, see for example Mankiw and Whinston (1986).
} 
(2005) review a number of cases, including work on exclusive territory restrictions. They compare the estimated welfare effects of voluntary restraints with those of governmentmandated restraints. They conclude that voluntary restraints tend to have beneficial welfare effects, whereas mandated restraints tend to have detrimental effects. Our results appear to further strengthen this broad conclusion.

The paper is organized as follows. Section 2 describes the markets of pharmacies and physicians, with the entry and conduct regulations, and introduces the data set. Section 3 presents the econometric entry model and section 4 discusses the empirical results. Section 5 analyzes the implications for policy reform and section 6 concludes.

\section{The markets of pharmacies and physicians}

Health care markets are subject to extensive regulation in most countries. The regulations have often been motivated by efficiency considerations; Dranove and Satterthwaite (2000) provide an overview of the various market failures associated with the supply of basic health care services. In addition, equity concerns and private interests have often been invoked to explain the government interventions. In this section we provide a selective overview of the health care markets in which the pharmacies and physicians operate in Belgium. We focus on those elements that motivate our econometric model. We begin with a discussion of the entry process, including the presence of geographic entry restrictions on the pharmacies as imposed by the Belgian government. We next discuss the general economic and regulatory factors influencing the nature of competitive interaction within and between the two professions. Finally, we provide descriptive statistics of our collected data set, documenting some of the discussion and introducing our subsequent econometric analysis.

\subsection{Entry and geographic restrictions}

Both pharmacies and physicians need to satisfy minimum educational standards. Physicians, which we define as general practitioners (as opposed to specialists), need to obtain a university degree in medical sciences. Until recently, every high school graduate was eligible to start this degree. Since 1998, there is an introductory examination at the start of the first year in one region of the country (Flanders) to restrict the number of incoming students. However, this potential entry restriction is irrelevant for our empirical analysis, which covers the year 2001 (i.e. before the 1998 incoming students graduated). In practice, only a minority of the students (about 25\%) with a medical degree choose to become a physician

(in the sense of a general practitioner). Other employment opportunities are to become a 
specialist, an occupational health officer, an expert for the health insurer, etc. There are no essential further restrictions to setting up a physician's practice. ${ }^{4}$ In particular, a physician can choose to locate an establishment anywhere in Belgium. According to the WIV (2002), the majority of physicians (about $78 \%$ in 2001) operate as a single-person establishment. In recent years, there has been a development to form associations of several physicians, but these are considerably less developed than in other countries.

Pharmacies also need to satisfy minimum educational standards; see Philipsen (2003) for a detailed review. A university degree in pharmaceutical sciences provides the right to independently prepare and sell drugs in an existing establishment. However, in contrast to the physicians' case, this degree is not sufficient to entitle one to set up a new establishment. Since 1974, there exists an establishment act, imposing geographic entry restrictions on the number of pharmacies based on population criteria. Many other European countries have adopted similar acts. The most comparable population-based establishment acts exist in Finland, France and Portugal. Other countries with geographic entry restrictions in some form include Spain, Italy and the U.K.

More specifically, the act stipulates that there should be no more than one pharmacy per 2, 000 inhabitants in small municipalities (with fewer than 7,500 inhabitants); no more than one pharmacy per 2, 500 inhabitants in intermediate municipalities (with a number of inhabitants between 7,500 and 30,000); and no more than one pharmacy per 3,000 inhabitants in the larger municipalities. For example, in a municipality with 6,000 inhabitants, there can be no more than one pharmacy per 2,000 inhabitants, implying that there can be at most 3 pharmacies. The act provides slightly more lenience, i.e. lower threshold population levels, if the physical distance between a new candidate pharmacy and any incumbent is sufficient large. Because of the establishment act, people with a university degree in pharmaceutical studies have only two ways to start an independent pharmacy: either apply for a new establishment at a location where the entry restrictions are not yet binding, or buy an existing pharmacy from an incumbent. The latter is the more common event; it is often a transaction between an incumbent who has reached retirement age and a candidate pharmacist who has obtained several years of experience in the same or in another pharmacy. ${ }^{5}$

\footnotetext{
${ }^{4}$ There are some requirements of secondary importance. First, the Medical Committee needs to certify the medical degree and the applicant has to enroll with the medical association, the so-called "Order of Physicians". Second, it is necessary to register at the National Institute of Health Insurance (RIZIV), so that the medical consultation services to consumers can be covered by the health insurance companies.

${ }^{5}$ The average number of pharmacists (with a university degree) working in a pharmacy is 1.5 . Hence, as in the physicians' case, most pharmacies operate as single-person establishments.
} 


\subsection{Competitive interaction}

We first discuss the geographic dimension, showing that competitive interaction essentially takes place at the local level. Next, we discuss the relevant institutional factors determining the (local) competitive interaction within each of the professions and between the two professions.

\section{Competitive interaction at the geographic level}

Consistent with earlier health care studies, it is reasonable to define the relevant geographic markets at the town level. The population within each town is typically concentrated around the center, with the exception of the densely populated urban areas, which we will exclude from our sample. As will be discussed below, both physicians and pharmacies cannot engage in advertising or other active promotional selling activities, so that it is reasonable to expect that the patients' choices are largely guided by local information. Furthermore, survey evidence indicates that the majority of patients do indeed not travel outside their town to visit a physician. In the Netherlands, a country with similar demographic characteristics as Belgium, $85 \%$ of the patients travel less than 5 kilometers, which usually falls within the geographic boundaries of the town. Furthermore, $94 \%$ of the Belgian patients have a single fixed physician, which is conceivably located close to the patient's home. For the pharmacies, a recent study by the OFT (2003) finds that only $6 \%$ of the patients visit their pharmacy while commuting to work, further confirming the local nature of competitive interaction. Note that our market definition for assessing competitive interaction is narrower than the municipalities on which the establishment act is based: municipalities typically consist of 1-4 towns (59\% of municipalities with 1 town; $90 \%$ of the municipalities with 4 or fewer towns).

\section{Competitive interaction within each of the two professions}

Physicians provide medical consultations on a fee-for-service basis. A fixed price is negotiated between the government and the health insurer. Physicians are free to charge a higher price, but the social insurance companies do not reimburse patients for the extra price. In practice, only $15 \%$ of the physicians have not signed the fixed price agreement. Selfregulation traditionally prevented physicians from competing through advertising, though in recent years and under pressure of the European Commission there has been an increased tolerance towards informative advertising. While price and advertising competition have traditionally been quite limited, physicians have a broad range of other possible instruments to compete for patients: availability (consultation hours, waiting times and possibility to make appointment), quality and time spent on medical consultations (which can show a large variation among physicians), and willingness to provide medical prescriptions and sick-days. 
Pharmacies have the exclusive right to sell drugs. In contrast to most other countries, this exclusivity applies to both prescribed drugs and over-the-counter (OTC) drugs. The prices of drugs are fixed by the Ministry of Economic Affairs, after negotiations with the pharmaceutical companies and the pharmacies' association. The pharmacies obtain a fixed margin of $31 \%$ of the drug price, up to a ceiling of $7.44 €$ per package. Because this ceiling has not been adjusted, the average percentage margin has gradually declined from $28 \%$ in 1994 to $23 \%$ in 2001 (de Bruyn (1994) and De Bruyn (2006)). In sum, for most products there is essentially no price competition. ${ }^{6}$ Advertising has until recently also been prevented due to self-regulation by the pharmacies' association, but there are various potential non-price instruments: availability (opening hours), quality of service and advice, and the supply of an assortment of general care products.

To summarize, competition among physicians and among pharmacies has until recently been limited with respect to price and advertising instruments, but there are a variety of other possible instruments at their disposal to compete for patients. We will come back to this in the empirical analysis when interpreting our results on the effects of entry on competition.

\section{Competitive interaction between the two professions}

The two professions' core services are potentially strong complements: physicians provide medical consultations and prescribe drugs, while pharmacies are responsible for selling the drugs. As a result, the nearby presence of one profession could strongly benefit the other profession (since geographic proximity matters, as we discussed above). The degree of complementarity is however not perfect and it may actually be asymmetric: not all consultations end with a prescription, and several drugs can be sold by pharmacies without a prescription. If patients would often visit the physician without a subsequent visit to the pharmacy (because no drug was prescribed), then the presence of a pharmacy would only have a small impact on the physicians' profit. Hence, pharmacies would only be weak complements to physicians. Conversely, if patients would often visit a pharmacy without a preceding visit to the physician (because the drug requires no prescription or was prescribed by a specialist), then physicians would only be weak complements to pharmacies. The degree of complementarity in both directions is therefore an empirical question. The above study by the OFT (2003) suggests a strong complementary link between both professions: up to $47 \%$ of U.K. patients go to the pharmacy immediately after having visited their physician.

While the professions' core services are complementary, they regularly operate on each

\footnotetext{
${ }^{6}$ There is, however, some price competition for the pharmacists' own preparations and for some other general care products (such as cosmetics). But since these constitute a small fraction of overall sales, the overall extent of price competition is limited, just as in the physicians' case.
} 
other domain, so that they may also be viewed as providing substitute services. This has led to many conflicts between pharmacies and physicians. ${ }^{7}$ In addition to providing medical advice, physicians frequently offer free drugs to their patients, obtained from the pharmaceutical companies as a way to promote their products. The pharmacies do not oppose to such drug promotions per se, but they claim that the distribution should remain the exclusive right of the pharmacies. Conversely, pharmacies also provide services that are in the physicians' domain. They offer an increasing amount of independent medical advice to patients when selling their drugs. This development has actually been actively promoted by the European Commission: in the near future, pharmacies will be partly rewarded on a fee-forservice basis, rather than as a percentage of their sales, giving them additional incentives to provide medical advice; they will also obtain the right to substitute the prescribed drugs by equivalent but less expensive generic alternatives. Furthermore, even if physicians would not want to sell drugs and pharmacies would not want to provide medical advice, their services may be literally substitutable in a fair number of cases. In sum, while the professions' core services appear to be complementary, they may also be substitutable to some extent.

This discussion has largely focused on the demand-side factors influencing the extent of competitive interaction between pharmacies and physicians. In principle, competitive interaction may also stem from supply-side factors. For example, pharmacies and physicians may generate knowledge spill-overs and learning effects, which can affect both their variable and fixed costs. The health care literature we have surveyed has however not put emphasis on these sources of competitive interaction. We will therefore interpret our subsequent empirical findings on the strategic interdependence of entry decisions as largely stemming from the discussed demand-side sources.

\subsection{Overview of the data}

An overview of the data documents part of the above discussion, and introduces our subsequent econometric analysis. The data set contains information on 1, 136 markets in 2001, defined at the town-level as motivated by our earlier discussion of the relevant geographic markets. To reduce potential problems with overlapping markets, we do not include urban towns, which are defined by a population density of more than 800 inhabitants per $\mathrm{km}^{2}$ or a population of more than 15,000. This reduces our sample of towns to 847. We obtained similar conclusions based on the full sample of 1,136 towns. We have information on the number of active pharmacies and physicians per market. We combine this with information

\footnotetext{
${ }^{7} \mathrm{An}$ interesting discussion of the conflicts arising from competition between physicians and pharmacies is provided in an article of the Belgian newspaper De Standaard (08/06/2004), with the self-explanatory translated title "Why physicians want to sell drugs, and pharmacies want to provide medical consultations."
} 
on the demographic characteristics of each market. ${ }^{8}$

Table 1 presents counts of the observed market configurations, which we will model in our econometric analysis. For example, there are 142 markets with no pharmacies or physicians, and 58 markets with one pharmacy and two physicians. There are also several market configurations that never occur, e.g. three physicians and more than three pharmacies. More generally, the table shows that there is a quite strong correlation between the number of pharmacies and physicians; the correlation coefficient is 0.85 . This strong correlation may be due to common observed and unobserved factors influencing the profitability of pharmacies and physicians. However, our discussion above suggests that the correlation may also be due to the fact that both professions provide complementary services. Our econometric analysis will attempt to distinguish between these alternative possibilities (conditional on distributional assumptions).

The final row shows the percentage of all markets (broken down by the number of pharmacies), in which the geographic entry restriction imposed on the pharmacies is binding, in the sense that no additional pharmacies are allowed to enter by the establishment act. This will be important in our empirical analysis. The entry restrictions are binding for $82.3 \%$ of all the markets. Binding entry restrictions occur the least frequently in markets with two established pharmacies, but even here the percentage is quite large (74.7\%). Note that the entry restrictions are also frequently binding in markets without pharmacies. While this may seem counterintuitive, it follows from the fact that the markets (towns) are smaller than the municipalities on which the establishment act is based. It is therefore possible that no pharmacies are allowed to enter in one town, because there are already too many pharmacies in other towns of the same municipality. Note also that when the entry restrictions are binding, the establishment act may sometimes be violated. This is due to historical factors, since many pharmacies were set up in anticipation of the act, and these pharmacies were not forced to shut down at the moment the act was introduced. ${ }^{9}$ However, the excess number of pharmacies is generally small in these cases, and it is in any case not relevant for our econometric framework below.

$$
<\text { Table } 1>
$$

\footnotetext{
${ }^{8}$ The demographic characteristics were provided by the NIS (National Institute of Statistics), Ecodata (Federal Government Agency for Economics) and the RSZ (the National Institute of Social Security). The information on the number of pharmacies and physicians is from RIZIV (the National Institute of Health Insurance). In accordance with RIZIV, a physician is defined as a general practitioner who has more than 49 patients and has annually more than 199 consultations, of which more than $0.9 \%$ are house visits. This is a rather broad definition, but our results are robust when we use stricter definitions.

${ }^{9}$ In some cases a violation of the entry restrictions may be due to an exception clause in the act, which allows an additional entry under certain circumstances (population and distance of existing pharmacies).
} 
Table 2 provides summary statistics on the demographic variables, which may affect the profitability of both professions. We include information on population size, the percentage of young people (under the age of 18), the percentage of elderly (over the age of 65), the percentage of foreigners, the unemployment rate, mean income, and a dummy variable to account for structural differences between the region of Flanders and Wallonia.

$<$ Table $2>$

\section{The entry model}

Section 2 shows that several central institutional facts should be incorporated in our empirical framework. First, the interaction within and between pharmacies and physicians is local, and it is reasonable to define the geographic markets at the town level. Second, pharmacies and physicians on balance provide largely complementary services, so that entry in one profession may have a positive net impact on the profitability of entry in the other profession. Third, the entry of pharmacies is regulated. For each municipality (typically consisting of about 1-4 towns) there is a maximum number of pharmacies based on population criteria. Entry by physicians is not restricted on a geographic basis. Fourth, conduct is regulated: pharmacies received a regulated average gross margin of $23 \%$ in 2001, and physicians are paid on a fee for service basis. Both professions are also subject to advertising restrictions, but can potentially compete in other dimensions (e.g. opening hours, quality of service).

Our entry model will incorporate these features. The model fits in the recent empirical entry literature, as initiated by Bresnahan and Reiss (1990, 1991) and Berry (1992). This literature models entry as a strategic game, and aims to draw inferences about unobserved payoffs - a latent variable - from the equilibrium relationship between the observed market structure and market characteristics, such as market size. Our own model is a static one, in the spirit of Mazzeo (2002); for dynamic entry models see Pakes, Ostrovsky and Berry (2005) and their review of other recent work. Mazzeo distinguishes between two types of substitute firms, and he models the total number of firms of each type as the (unique) equilibrium outcome of a strategic free entry game. We extend the static entry literature in two respects. First, we account for the fact that entry may not be free, i.e. there may be binding entry restrictions for one of the two types of firms (pharmacies). Second, we allow for the possibility that the entry decisions of firms of different types are (net) strategic complements, rather than strategic substitutes. ${ }^{10}$ Vives (2005) provides a background overview of games with

\footnotetext{
${ }^{10}$ Previous work has not considered the possibility that entry is restricted. As far as we know, the possibility that entry decisions are strategic complements has also not been treated within an equilibrium entry model,
} 
strategic complementarities. His framework includes applications when the firms' decision variables are continuous, but it can also be applied to situations where the decision variables are discrete as in our entry context.

\subsection{Payoffs}

There are two types of firms, $i=1,2$. Firms of type 1 are pharmacies, and firms of type 2 are physicians. Each firm decides whether or not to enter the market. The entry decisions can be summarized by the total number of firms of each type $i$ entering the market, as denoted by the random variable $N_{i}$. Equilibrium realizations of this random variable are denoted by $n_{i}$. Because of the geographic entry restrictions the maximum allowed number of pharmacies in the market is $\bar{n}_{1}$, so $N_{1} \leq \bar{n}_{1}$. Following the discussion in section $2, \bar{n}_{1}$ is equal to the maximum allowed number of pharmacies in the municipality minus the number of firms in the other markets of the same municipality. If $N_{1}<\bar{n}_{1}$, the entry restriction is not binding in equilibrium; if $N_{1}=\bar{n}_{1}$ the entry restriction is binding.

Firms of the same type are identical, i.e. there is no heterogeneity between firms of the same type, similar to Mazzeo (2002). Hence, firms of the same type have the same payoff functions. If a firm of either type $i$ does not enter, its payoffs are normalized to zero. If a firm of type $i$ enters, its payoffs depend on the total number of entering firms of both types, as given by:

$$
\pi_{i}^{*}\left(N_{1}, N_{2}\right)=\pi_{i}\left(N_{1}, N_{2}\right)-\varepsilon_{i}
$$

where $\pi_{i}\left(N_{1}, N_{2}\right)$ is the deterministic component of payoffs, and $\varepsilon_{i}$ is a random component, unobserved to the econometrician. The precise relationship between the payoffs and the number of firms of each type reflects the nature of competitive interaction. Our first assumption is that entry decisions by firms of the same type are strategic substitutes. Davis (2006) provides a careful analysis of this assumption in a general class of quantity games including discrete entry games. ${ }^{11}$ In our framework, the assumption that entry decisions by

although there are some related papers. Sweeting (2005) considers a coordination game to study the timing of radio commercials (in a different incomplete information setting). Cohen and Mazzeo (2005) investigate whether branch investments are strategic complements. Since the branching decision may take more than two values, the dimension of the problem becomes very high, making it computationally difficult to develop the equilibrium conditions for the number of branches. As an alternative, they therefore specify reaction functions for the branching decisions (accounting for endogeneity of the rivals' choices).

${ }^{11}$ See in particular Davis' Assumption 3 and his subsequent discussion. Let $s_{j}$ denote firm $j$ 's action and $s_{-j}$ firm $j$ 's competitors actions. In Davis' framework, a single index function $Q\left(s_{j}, s_{-j}\right)$ summarizes the effects of the competitors' actions on profits, whereas in our framework there are two index functions (for the two types of firms). Our framework is however more restrictive in several other respects: firms (of the same type) are identical, a firm's action is either to enter or not to enter, $s_{j}=\{1,0\}$, and the index function (for 
same-type firms are strategic substitutes means that a firm's marginal profits from entering (i.e. $\left.\pi_{i}^{*}\left(N_{1}, N_{2}\right)-0\right)$ decreases when another firm of the same type decides to enter. This simply amounts to assuming that a firm's payoffs (under entry) are decreasing in the number of firms of the same type.

Assumption 1. (Entry decisions by firms of the same type are strategic substitutes)

$$
\begin{aligned}
& \pi_{1}\left(N_{1}+1, N_{2}\right)<\pi_{1}\left(N_{1}, N_{2}\right) \\
& \pi_{2}\left(N_{1}, N_{2}+1\right)<\pi_{2}\left(N_{1}, N_{2}\right)
\end{aligned}
$$

for all $N_{1}$ and $N_{2}$. This assumption is consistent with the previous empirical entry literature, and is central to characterize the Nash equilibrium outcomes below.

Regarding firms of different types, we assume that their entry decisions are strategic complements or independent. This is in line with our background discussion in section 2, which showed that the pharmacies' and physicians' core services are complementary even though some degree of substitutability between related services cannot be ruled out. Intuitively, we assume that a firm's payoffs are increasing in the number of firms of the other type, but not by too much.

Assumption 2. (Entry decisions by firms of different types are strategic complements or independent)

$$
\begin{aligned}
& \pi_{1}\left(N_{1}, N_{2}\right) \leq \pi_{1}\left(N_{1}, N_{2}+1\right) \\
& \pi_{2}\left(N_{1}, N_{2}\right) \leq \pi_{2}\left(N_{1}+1, N_{2}\right) \\
& \pi_{1}\left(N_{1}+1, N_{2}+1\right)<\pi_{1}\left(N_{1}, N_{2}\right) \\
& \pi_{2}\left(N_{1}+1, N_{2}+1\right)<\pi_{2}\left(N_{1}, N_{2}\right)
\end{aligned}
$$

for all $N_{1}$ and $N_{2}$. Assumption 2 (a) states that a firm's payoffs (under entry) are either increasing or independent of the number of firms of the other type. Hence, the marginal profits from entering (i.e. $\pi_{i}^{*}\left(N_{1}, N_{2}\right)$-0) weakly increase when a firm of the other type decides to enter, so that their entry decisions are (weak) strategic complements. Assumption 2 (b) says that the extent of strategic complementarity between firms of different types is weaker than the extent of strategic substitutability between firms of the same type. Hence, payoffs decrease when there is an additional firm of both the own type and the other type. ${ }^{12}$ It is also

a single type) is simply the number of firms, i.e. the sum of all entry decisions, $N=Q\left(s_{j}, s_{-j}\right)=\sum_{k=1}^{K} s_{k}$, where $K$ is the number of potential entrants.

${ }^{12}$ Strictly speaking, we only require one of the pair of inequalities in Assumption 2 (b) to be strict. 
possible to reverse Assumption 2, i.e. assume that entry decisions by firms of different types are strategic substitutes (but not by too much). This would be similar to Mazzeo (2002). We have also considered such a model, but found that it was not supported by the data.

Note finally that our assumptions allow for the possibility of asymmetries in strategic interdependence. Hence, consistent with our discussion in section 2, it is possible that the entry decision of a pharmacy has a stronger positive impact on a physician than vice versa. The reverse is also possible. We will come back to this when discussing our empirical results.

Based on Assumptions 1 and 2, we can now derive the equilibrium number of firms and the implied likelihood function to be taken to the data. In the empirical analysis, we will verify whether these assumptions are indeed satisfied at the obtained parameter estimates.

\subsection{Equilibrium with nonbinding geographic entry restrictions}

When entry restrictions are not binding, i.e. $N_{1}<\bar{n}_{1}$, each firm freely decides whether or not to enter, given the entry decisions of the other firms. As is well-known, there are many purestrategy Nash equilibria in this entry game. Bresnahan and Reiss (1990) resolve this problem in two alternative ways. First, they aggregate the non-unique Nash equilibrium outcomes to obtain an econometric model for the total number of firms entering in a Nash equilibrium. In their application in which all firms are substitutes, this yields a unique prediction for the total number of entering firms. Second, they put additional structure to the entry game and assume that firms move sequentially. This alternative approach yields a unique subgame perfect Nash equilibrium at the disaggregate firm level. Mazzeo (2002) can be viewed as a combination of both approaches: he specifies a model for the total number of firms per type entering in a Nash equilibrium, and then refines the Nash equilibrium to obtain a unique prediction for the total number of firms per type. ${ }^{13}$ We take a related approach here.

The market configuration $\left(n_{1}, n_{2}\right)$ is a Nash equilibrium outcome if and only if the random component of profits $\varepsilon=\left(\varepsilon_{1}, \varepsilon_{2}\right)$ satisfies the following conditions:

$$
\begin{aligned}
& \pi_{1}\left(n_{1}+1, n_{2}\right)<\varepsilon_{1} \leq \pi_{1}\left(n_{1}, n_{2}\right) \\
& \pi_{2}\left(n_{1}, n_{2}+1\right)<\varepsilon_{2} \leq \pi_{2}\left(n_{1}, n_{2}\right)
\end{aligned}
$$

When (2) is satisfied, $n_{1}$ firms of type 1 , and $n_{2}$ of type 2 find it profitable to enter, and no additional firm of either type has an incentive to enter; hence $\left(n_{1}, n_{2}\right)$ is indeed a Nash equi-

\footnotetext{
${ }^{13}$ There have also been alternative approaches to the multiplicity of equilibria in static entry games. Ciliberto and Tamer (2004) draw inference from a class of models rather than refining the equilibrium to obtain a unique prediction. Seim (2005) introduces incomplete information to the entry game. While her model does not obtain uniqueness in general, uniqueness obtains under reasonable parameter restrictions and it can be verified for the obtained parameter estimates.
} 
librium outcome. If $\varepsilon$ has full support, Assumption 1 guarantees that there are realizations of $\varepsilon$ for which (2) holds, so that the market configuration $\left(n_{1}, n_{2}\right)$ is observed with positive probability.

However, $\left(n_{1}, n_{2}\right)$ may show multiplicity with other Nash equilibrium outcomes for some realizations of $\varepsilon$. Intuitively, the multiplicity stems from coordination problems, as is illustrated in Figure 1. The bold lines delineate the areas of $\varepsilon$ for which the market configurations $(1,2)$ and $(2,3)$ are the Nash equilibrium outcomes. The shaded rectangle is the area of overlap, where both market configurations are Nash equilibrium outcomes. Note that the area of multiplicity would disappear if firms are independent, i.e. if the conditions in Assumption 2 (a) hold with equality, so that $\pi_{1}(2,2)=\pi_{1}(2,3)$ and $\pi_{2}(1,3)=\pi_{2}(2,3)$. As the extent of complementarity increases, the area of multiplicity increases. Figure 2 shows an extreme case of strong complementarity. In this case, the entire area of $\varepsilon$ for which $(1,2)$ is a Nash equilibrium outcome is a subset of the area of $\varepsilon$ for which $(2,3)$ is a Nash equilibrium. Hence, there would be no $\varepsilon$ for which $(1,2)$ is a Nash equilibrium without $(2,3)$ also being one. Assumption 2(b) rules out this possibility, since it requires that $\pi_{1}(2,3)<\pi_{1}(1,2)$ and $\pi_{2}(2,3)<\pi_{2}(1,2)$.

\section{$<$ Figures 1 and $2>$}

In general, the multiplicity of Nash equilibrium outcomes can be characterized as follows. If firms of different types are independent, i.e. Assumption 2(a) holds with equality, then the market configuration $\left(n_{1}, n_{2}\right)$ is the unique Nash equilibrium outcome in the area of $\varepsilon$ satisfying (2). In contrast, if the entry decisions of firms of different types are strategic complements, i.e. Assumption 2(a) holds with strict inequality, then $\left(n_{1}, n_{2}\right)$ may show multiplicity with other Nash equilibrium outcomes for some realizations of $\varepsilon$. In the Appendix, we show the following three results:

1. $\left(n_{1}, n_{2}\right)$ may only show multiplicity with Nash equilibrium outcomes of the form $\left(n_{1}+\right.$ $\left.m, n_{2}+m\right)$, where $m$ is a positive or a negative integer. For example, if $(1,2)$ is a Nash equilibrium outcome, there may be multiplicity with, say, $(0,1)$ or $(2,3)$ or $(3,4)$ but not with $(2,4)$.

2. $\left(n_{1}, n_{2}\right)$ necessarily shows multiplicity with $\left(n_{1}+1, n_{2}+1\right)$ and $\left(n_{1}-1, n_{2}-1\right)$. The area of multiplicity with $\left(n_{1}+1, n_{2}+1\right)$ is given by:

$$
\begin{aligned}
& \pi_{1}\left(n_{1}+1, n_{2}\right)<\varepsilon_{1} \leq \pi_{1}\left(n_{1}+1, n_{2}+1\right) \\
& \pi_{2}\left(n_{1}, n_{2}+1\right)<\varepsilon_{2} \leq \pi_{2}\left(n_{1}+1, n_{2}+1\right)
\end{aligned}
$$


and similarly for $\left(n_{1}-1, n_{2}-1\right)$.

3. While $\left(n_{1}, n_{2}\right)$ may also show multiplicity with $\left(n_{1}+m, n_{2}+m\right)$ for $m>1$ or $m<1$, these areas of multiplicity are necessarily a subset of the areas of multiplicity with $\left(n_{1}+1, n_{2}+1\right)$ and $\left(n_{1}-1, n_{2}-1\right)$.

Taken together, these results imply that the areas of $\varepsilon$ for which $\left(n_{1}, n_{2}\right)$ shows multiplicity with any other Nash equilibrium outcome are simply given by the areas of overlap with the outcomes $\left(n_{1}+1, n_{2}+1\right)$ (given by $\left.(3)\right)$ and $\left(n_{1}-1, n_{2}-1\right)$.

The multiplicity problem follows from the weak structure implied by the Nash equilibrium concept. To obtain unique predictions, we put additional structure on the entry game. We assume that firms make their entry decisions sequentially, i.e. after observing all previous entry decisions, and impose the subgame perfect Nash equilibrium refinement. ${ }^{14}$ When entry decisions of other-type firms are strategic complements, it is not necessary to make specific assumptions regarding the exact ordering of entry moves. This additional structure makes it possible to assign a unique subgame perfect equilibrium outcome to every realization of $\varepsilon$. Suppose $\varepsilon$ is such that both $\left(n_{1}, n_{2}\right)$ and $\left(n_{1}+m, n_{2}+m\right)$ are Nash equilibrium outcomes (with $m$ a positive or negative integer). The outcome with the fewest number of firms cannot be subgame perfect, since there would then always be an additional firm of one type with an incentive to enter, in anticipation of triggering further entry by a firm of the other type as well. Hence, when there are multiple Nash equilibrium outcomes, the one with the largest number of firms is the unique subgame perfect equilibrium. Making use of our earlier characterization of the multiplicity of Nash equilibrium outcomes, it immediately follows that $\left(n_{1}, n_{2}\right)$ will be a subgame perfect Nash equilibrium outcome if and only if (i) $\varepsilon$ satisfies conditions (2) and (ii) $\varepsilon$ does not satisfy conditions (3). This can be illustrated on Figure 1. The market configuration $(1,2)$ is a subgame perfect Nash equilibrium outcome if and only if $\varepsilon$ falls in the relevant area bounded by the bold lines, minus the shaded area in the lower left corner.

Assuming that $\varepsilon$ has a bivariate density $f(\cdot)$, it is now possible to derive the probability that the market configuration $\left(n_{1}, n_{2}\right)$ will be observed as the unique subgame perfect

\footnotetext{
${ }^{14}$ This approach is in the spirit of Mazzeo (2002), but adapted to the circumstances of our application to health care professions. Mazzeo assumes that firms can choose their type at or after entering. We instead assume that firms first choose their type. The potential entrants of each type subsequently make their entry decision without being able to change their type. This is a reasonable assumption in our setting, since training to become physician or pharmacy is costly and time consuming. In practice, physicians and pharmacies rarely retrain. Our assumption that firms choose their type before entering yields subgame perfect equilibrium conditions that differ somewhat from Mazzeo (2002).
} 
equilibrium outcome when entry restrictions are not binding:

$$
\begin{aligned}
\operatorname{Pr}\left(N_{1}=\right. & \left.n_{1}, N_{2}=n_{2}\right)=\int_{\pi_{1}\left(n_{1}+1, n_{2}\right)}^{\pi_{1}\left(n_{1}, n_{2}\right)} \int_{\pi_{2}\left(n_{1}, n_{2}+1\right)}^{\pi_{2}\left(n_{1}, n_{2}\right)} f\left(u_{1}, u_{2}\right) \mathrm{d} u_{1} \mathrm{~d} u_{2} \\
& -\int_{\pi_{1}\left(n_{1}+1, n_{2}\right)}^{\pi_{1}\left(n_{1}+1, n_{2}+1\right)} \int_{\pi_{2}\left(n_{1}, n_{2}+1\right)}^{\pi_{2}\left(n_{1}+1, n_{2}+1\right)} f\left(u_{1}, u_{2}\right) \mathrm{d} u_{1} \mathrm{~d} u_{2} .
\end{aligned}
$$

\subsection{Equilibrium with binding geographic entry restrictions}

Non-geographic entry restrictions, e.g. minimum requirements of competency, are common

to all firms and do not require a special treatment. They directly enter the payoffs of the firms through observable or unobservable factors affecting fixed costs.

Binding geographic entry restrictions, in contrast, require modifying the traditional free entry framework. In this case $N_{1}=\bar{n}_{1}$, so that there may be type 1 firms (pharmacies) that have an incentive to enter but are not able to do so because of the entry restriction. This has the following immediate implication. From the market configuration $\left(\bar{n}_{1}, n_{2}\right)$ it is no longer possible to infer that entry by $\bar{n}_{1}+1$ firms would be unprofitable. Hence, with binding entry restrictions the market configuration $\left(\bar{n}_{1}, n_{2}\right)$ is a Nash equilibrium outcome if and only if $\varepsilon$ satisfies the following conditions:

$$
\begin{aligned}
\varepsilon_{1} & \leq \pi_{1}\left(\bar{n}_{1}, n_{2}\right) \\
\pi_{2}\left(\bar{n}_{1}, n_{2}+1\right)<\quad & \varepsilon_{2} \leq \pi_{2}\left(\bar{n}_{1}, n_{2}\right) .
\end{aligned}
$$

For firms of type 2 these conditions are still the same as in (2). For firms of type 1 they are different, since it is no longer possible to infer a lower bound on profits from observing $\left(\bar{n}_{1}, n_{2}\right)$. This actually simplifies the problem of multiple Nash equilibrium outcomes. With nonbinding entry restrictions, we showed that $\left(n_{1}, n_{2}\right)$ may only show multiplicity with Nash equilibrium outcomes of the form $\left(n_{1}+m, n_{2}+m\right)$, with $m$ either a positive or a negative integer. When the entry restrictions are binding, it is immediately obvious that there can no longer be such multiplicity for positive integers $m$. Hence, $\left(\bar{n}_{1}, n_{2}\right)$ can only have multiplicity with equilibria of the form $\left(\bar{n}_{1}+m, n_{2}+m\right)$, for negative integers $m$. However, similar to the case of nonbinding entry restrictions, the equilibrium with the fewer number of firms cannot be selected as the subgame perfect Nash equilibrium. The market configuration $\left(\bar{n}_{1}, n_{2}\right)$ is therefore the unique subgame perfect Nash equilibrium if and only if $\varepsilon$ satisfies (5).

The probability of observing the market configuration $\left(\bar{n}_{1}, n_{2}\right)$ as the subgame perfect 
Nash equilibrium when entry restrictions are binding becomes:

$$
\operatorname{Pr}\left(N_{1}=\bar{n}_{1}, N_{2}=n_{2}\right)=\int_{-\infty}^{\pi_{1}\left(\bar{n}_{1}, n_{2}\right)} \int_{\pi_{2}\left(\bar{n}_{1}, n_{2}+1\right)}^{\pi_{2}\left(\bar{n}_{1}, n_{2}\right)} f\left(u_{1}, u_{2}\right) \mathrm{d} u_{1} \mathrm{~d} u_{2} .
$$

\subsection{Econometric specification}

We can now specify the likelihood function for our cross-section of markets on observed market configurations and the corresponding market characteristics. We suppress a market subscript $m$ indexing the unit of observation. For both markets with nonbinding and binding entry restrictions, there is a unique subgame perfect Nash equilibrium outcome for every possible realization of $\varepsilon$. Hence, the probabilities of observing a market configuration, as derived by (4) and (6), can be sensibly used to construct the likelihood function. Defining a dummy variable $d=1$ if $N_{1}<\bar{n}_{1}$ and $d=0$ otherwise, the contribution to the likelihood function of a representative observed market configuration is:

$$
l=d \operatorname{Pr}\left(N_{1}=n_{1}, N_{2}=n_{2}\right)+(1-d) \operatorname{Pr}\left(N_{1}=\bar{n}_{1}, N_{2}=n_{2}\right),
$$

where the probability terms are defined above by (4) and (6).

Specify the density $f(\cdot)$ as the bivariate normal density, with a parameter $\rho$ measuring the correlation between $\varepsilon_{1}$ and $\varepsilon_{2}$. There are some interesting special cases of this model. First, suppose that the payoffs are independent of the number of firms of the other type, i.e. Assumption 2(a) holds with equality, so $\pi_{i}^{*}\left(N_{1}, N_{2}\right)=\pi_{i}^{*}\left(N_{i}\right)$ for each type $i$. In this case the second term in (4) vanishes, so that the model reduces to a bivariate ordered probit model with censoring, where the censoring refers to observations where the entry restrictions are binding. Second, if in addition the entry restriction is not binding for any observation, the model reduces to an uncensored bivariate ordered probit model. Third, if the correlation parameter $\rho=0$, we end up with two traditional ordered probit models, one for each type, as estimated by Bresnahan and Reiss (1991) and several subsequent contributions. In the

empirical analysis, we will also present the results from the first two special cases and compare it with the general model.

It remains to specify the payoffs $\pi_{i}^{*}\left(N_{1}, N_{2}\right)$ entering the likelihood function through the probabilities (4) and (6). Consider the following linear specification:

$$
\pi_{i}^{*}\left(N_{1}, N_{2}\right)=\lambda_{i} \ln (S)+X \beta_{i}-\alpha_{i}^{j}+\gamma_{i}^{k} / N_{i}-\varepsilon_{i}
$$

The variable $S$ is market size, measured by the number of consumers (population), $X$ is 
a vector of other observed market characteristics, such as average income, percentage of elderly, and $\lambda_{i}$ and $\beta_{i}$ are the corresponding type-specific parameters. The parameters $\alpha_{i}^{j}$ and $\gamma_{i}^{k}$ are fixed effects for type $i$ when there are, respectively, $j$ firms of the own type and $k$ firms of the other type.

The fixed effects $\alpha_{i}^{j}$ are similar to the "cut-values" in simple ordered probit models, and measure the effect of $j$ firms of the own type on payoffs. ${ }^{15}$ The fixed effects $\gamma_{i}^{k}$ measure the effect of $k$ firms of the other type on payoffs, and reflect the extent of strategic complementarity between the entry decisions of different types. One may reasonably expect the complementarity effect to be stronger when there are few firms of the own type. We incorporate this by dividing $\gamma_{i}^{k}$ by the number of firms of the own type. ${ }^{16} \mathrm{~A}$ more general approach would be to specify a full set of fixed effects $\alpha_{i}^{j k}$ for every market configuration, instead of the additive specification $\alpha_{i}^{j}+\gamma_{i}^{k} / N_{i}$. This more general specification would however require a too large number of parameters to be estimated.

As is common in discrete choice models, the scale of the payoffs is not identified. To proceed with estimation, we restrict the standard deviation of $\varepsilon_{i}, \sigma_{i}$, to be equal to one. This restriction is irrelevant for our empirical analysis in section 4 . In our counterfactual analysis in section 5, however, we need to identify the scale of the payoffs, so we will then put additional structure on the payoffs. Apart from the scaling issue, the fixed effects are not all identified. For each type $i$ we set the first own-type fixed effect to zero, i.e. $\alpha_{i}^{1}=0 .{ }^{17}$ Furthermore, for each type $i$ we set $\gamma_{i}^{0}=0$.

Note that the strategic complementarities $\left(\right.$ the $\gamma_{i}^{k}$ ) are identified through our parametric assumptions. Intuitively, conditional on observed market characteristics the number of pharmacies and physicians may be correlated because of strategic complementarities (captured through the $\gamma_{i}^{k}$ ) or because of unobserved market characteristics affecting both professions payoffs (captured through the correlation parameter $\rho$ ). We distinguish between both possibilities based on the assumption that the error terms have a bivariate normal distribution. Other entry models with two or more types make similar parametric assumptions to obtain identification, e.g. Mazzeo (2002). ${ }^{18}$ To identify the strategic complementarities

\footnotetext{
${ }^{15}$ Some studies simply include the number of own-type firms as an explanatory variable, i.e. they include a term $-\alpha_{i} N_{i}$ instead of the fixed effects $\alpha_{i}^{j}$. This is more restrictive, as it assumes that the differences between two consecutive fixed effects are always the same $\left(\alpha_{i}\right)$.

${ }^{16}$ This has the intuitive implication that the effect of an other-type entrant on the aggregate profits of all own-type firms is independent of the number of own-type firms. Not dividing $\gamma_{i}^{k}$ by $N_{i}$ would imply that the effect of an other-type entrant on the aggregate own-type profits would increase with the number of own-type firms.

${ }^{17}$ The constant term $\beta_{i}^{0}$ in the vector $\beta_{i}$ then becomes identified. Alternatively, one can normalize $\beta_{i}^{0}=0$, and estimate $\alpha_{i}^{1}$.

${ }^{18}$ Mazzeo (2002) also assumes a normal distribution to identify the effects of other-type firm entry decisions, which are strategic substitutes in his case. While he does not estimate $\rho$, he performs a robustness analysis
} 
non-parametrically would require appropriate exclusion restrictions, i.e. specifying certain market characteristics that affect either the pharmacies' payoffs or the physicians' payoffs and not both. Since there are no obvious such restrictions in our application, we rely on our parametric assumptions to obtain identification. ${ }^{19}$

Assumptions 1 and 2 imply that the model is internally consistent if the estimated fixed effects $\alpha_{i}^{j}$ and $\gamma_{i}^{k}$ entering (8) satisfy the following conditions for all $i, j$ and $k$ :

$$
\begin{aligned}
\alpha_{i}^{j+1} & >\alpha_{i}^{j} \\
\gamma_{i}^{k+1} & \geq \gamma_{i}^{k} \\
\alpha_{i}^{j+1}-\gamma_{i}^{k+1} /\left(N_{i}+1\right) & >\alpha_{i}^{j}-\gamma_{i}^{k} / N_{i} .
\end{aligned}
$$

Since we normalized $\alpha_{i}^{1}=0$ and $\gamma_{i}^{0}=0$, it also follows that the fixed effects $\alpha_{i}^{j}$ and $\gamma_{i}^{k}$ should all be positive. The first row of inequalities in (9) simply says that an additional firm of the own type decreases the payoffs. ${ }^{20}$ The second row says that an additional firm of the other type increases the payoffs. Finally, the third row states that an additional firm of both types reduces the payoffs. In the empirical analysis, we will verify whether these conditions are satisfied. If they are, the estimates are consistent with the initial assumptions of the model.

\section{Empirical analysis}

Our empirical entry model with entry restrictions and strategic complementarities is given by (7), where the probabilities are defined by (4) and (6) and the payoffs are given by (8). The model is internally consistent if Assumptions 1 and 2 are satisfied, i.e. if the estimated own-type and other-type fixed effects $\alpha_{i}^{j}$ and $\gamma_{i}^{k}$ satisfy the conditions in (9).

There may be up to 11 pharmacies and up to 21 physicians in a market, implying a large number of fixed effects $\alpha_{i}^{j}$ and $\gamma_{i}^{k}$. It is necessary to impose restrictions on the pharmacies' own-type fixed effects $\alpha_{1}^{j}$, since the entry restrictions are always binding in markets with more than 4 pharmacies: for $j>4$, we therefore restrict $\alpha_{1}^{j}$ such that there is no further

of his results by assuming alternative values of $\rho$.

${ }^{19}$ This relates closely to the identification issues encountered in measuring complementarities in organizational design. Athey and Stern (2003) develop a structural framework to identify complementarities and show the importance of proper exclusion restrictions. Miravete and Pernias (2006) apply their framework using a maximum likelihood approach. Athey and Stern's framework is designed to identify complementarities of discrete choices by a single decision maker, whereas our entry framework looks at strategic complementarities of choices of two decision makers. However, the identification issues are similar.

${ }^{20} \mathrm{This}$ is similar to the requirement of the cut-points in traditional ordered probit models. The condition $\alpha_{i}^{j+1}>\alpha_{i}^{j}$ is a sufficient but not a necessary condition for Assumption 1 to be satisfied. The necessary and sufficient condition is slightly weaker, i.e. $\alpha_{i}^{j+1}>\alpha_{i}^{j}-\gamma_{i}^{k} /\left(\left(N_{i}\left(N_{i}+1\right)\right)\right.$. We present the sufficient condition, since it is easier to interpret in the empirical analysis, and since it was always met anyway. 
competitive entry effect. ${ }^{21}$ To estimate the other-type fixed effects, $\gamma_{i}^{k}$, we impose restrictions following a "bottom-up" approach: we begin with a limited number of other-type fixed effects and then add more until they no longer differ significantly from the previous one. We end up with a specification with one significant other-type fixed effect in the pharmacies' payoffs, $\gamma_{1}^{1}$, and four significant other-type fixed effects in the physicians' payoffs, $\gamma_{2}^{1} \ldots \gamma_{2}^{4}$ (where we set $\gamma_{1}^{k}=\gamma_{1}^{1}$ for $k>1$, and $\gamma_{2}^{k}=\gamma_{2}^{4}$ for $k>4$ ). The model is internally consistent, i.e. the estimated parameters satisfy all the conditions given by (9). Note that we also estimated an alternative model, in which the entry decisions of firms of different types are strategic substitutes (the reverse of Assumption 2). However, we found that the estimated parameters often violate that model's assumptions, i.e. the other-type firms often have a positive effect on payoffs, while the assumption of strategic substitutes requires the opposite. See Schaumans and Verboven (2006) for details on that model.

Table 3 presents the parameter estimates. The specification in the third column is our general model, accounting for both entry restrictions and strategic complementarities. For comparison purposes, the specification in the first column presents the estimates of an uncensored bivariate ordered probit model, which assumes no binding entry restrictions and no strategic complementarities (all $\gamma_{i}^{k}=0$ ). The specification in the second column shows the estimates of a censored bivariate ordered probit model. This still assumes there are no complementarities, but it accounts for the fact that entry restrictions on pharmacies are binding in some of the markets.

A comparison between the first and the second column clearly demonstrates the importance of accounting for the presence of geographic entry restrictions on pharmacies. Several of the parameters change to a substantial extent. A Hausman test confirms that the parameters differ significantly across the two estimators (test-statistic of 531.9). Hence, the consistent model which accounts for the entry restrictions should be preferred. Furthermore, a comparison between the second and the third column shows that the $\gamma_{i}^{k}$ are jointly significant (likelihood ratio test statistics of 41.78). This indicates that there are significant strategic complementarities between the entry decisions of pharmacies and physicians. These estimates take into account that the error terms entering the two professions' payoffs may be correlated, as captured by the parameter $\rho$. Recall however our earlier discussion that we

\footnotetext{
${ }^{21}$ To obtain these restrictions on $\alpha_{1}^{j}$, for $j>4$, we start from Bresnahan and Reiss' (1991) entry thresholds measures of competition. Define the entry thresholds $S_{i}^{j, k}$ as the market size at which the $j$-th firm of type $i$ would just be willing to enter when there are $k$ firms of the other type, i.e. the market size such that (8) is equal to zero. If the per-firm entry threshold for the $j$-th own-type entrant is the same as that of the $(j-1)$-th own-type entrant (given that there are no other type firms), there is no competititve entry effect. Using (8), it can be verified that this is the case if $\alpha_{1}^{j}=\alpha_{1}^{j-1}+\lambda_{1} \ln \left(\left(N_{1}-1\right) / N_{1}\right)$. Hence, we impose this restriction on the pharmacies' own-type effects for $j>4$.
} 
do not identify the strategic complementarities based on exclusion restrictions, but rather based on our parametric assumptions, including the bivariate normal distribution for the error terms.

$$
<\text { Table } 3>
$$

We now discuss the parameter estimates of the general entry model in more detail. Market size, as measured by population, is the most important market characteristic affecting the pharmacies' and physicians' payoffs. This is consistent with the results from previous entry models, such as Bresnahan and Reiss (1991). In line with expectations, the population's age distribution has an important impact on payoffs. More specifically, the percentage of elderly in a market has a positive and significant effect on both professions' payoffs; the effect is stronger for the pharmacies. ${ }^{22}$ The other market characteristics only have a significant effect on the payoffs of one of the two professions. The percentage of foreigners has a negative effect on payoffs, but the effect is significant only in the case of physicians. Physicians do not obtain significantly different payoffs in markets with higher unemployment, whereas pharmacies tend to obtain significantly higher payoffs in such markets, consistent with other studies showing that the unemployed tend to consume more drugs. Income per capita positively and significantly affects the physicians' payoffs. Finally, there are some regional differences: payoffs to physicians are significantly lower in the region of Flanders than in the other two regions (Brussels and Wallonia). This may be due to either different medical consumption habits or to better alternative employment opportunities in the region of Flanders.

The own-type fixed effects $\alpha_{i}^{j}$ are all positive and show an increasing pattern, as required by the first condition in (9). This implies that additional entry by firms of the same type lowers payoffs (strategic substitutes). The same pattern occurs for the other-type fixed effects $\gamma_{i}^{k}$, satisfying the second condition in (9). This means that additional entry by firms of different types raises payoffs (strategic complementarity). Finally, one can verify that the third condition in (9) is satisfied for all observed market configurations. Intuitively, this means that the extent of complementarity between firms of different types is lower than the extent of substitutability between firms of the same type.

Note that the strategic complementarities implied by the other-type effects $\gamma_{i}^{k}$ are asymmetric: pharmacies tend to yield larger benefits to physicians than vice versa. As discussed in section 2, such an asymmetry in complementarities could not be ruled out a priori. It can be interpreted as follows. On the one hand, a visit to the physician may rather likely result in

\footnotetext{
${ }^{22}$ This is also the case when we replace the percentage of old ( $>65$ years) by the percentage of "very old" (>80 years). If we include both variables, only the second has a significant effect. The percentage of young $(<18$ years) does not have a significant effect. We also re-estimated the model using the percentage of "kids" $(<10$ or $<5$ years) instead of the percentage of young and the parameter remains insignificant.
} 
a prescription and in a subsequent visit to the pharmacy. Hence, physicians tend to benefit strongly from the nearby presence of pharmacies. On the other hand, a visit to the pharmacy may often occur without a necessary preceding visit to the physician, because of over-thecounter drugs, or drugs prescribed by specialists. Hence, a pharmacy is less dependent on the nearby presence of physicians.

Further insights in the magnitude of the fixed effects can be obtained from the entry thresholds implied by the model. These are the critical market sizes (population levels) required to support a certain number of firms, for a given number of firms of the other type. Figure 3 shows the entry thresholds for pharmacies (top part) and physicians (bottom part) in relation to the number of firms. For both professions the critical market size to support a certain number of firms increases roughly proportionally with the number of firms. Following Bresnahan and Reiss (1991), one may interpret such a proportional relationship as evidence that additional entry does not lead to intensified competition. ${ }^{23}$ In section 2 we already discussed that neither pharmacies nor physicians can use price or advertising to compete. Our estimates thus imply that both professions do also not appear to use the other nonprice instruments (such as quality of service) in response to additional entry. Some caution is however warranted. In general, the entry threshold ratios are only informative about the change in competition in response to entry, but not about the level of competition to start with. In principle, it could thus be possible that even monopoly pharmacies and physicians already behave competitively, because of the threat of new entry as in contestable markets. However, at least for the pharmacies, this possibility appears to be rather unlikely. As Table 1 showed, the entry restrictions stemming from the establishment act are binding in the majority of the markets, so that most monopoly pharmacies are effectively protected from the threat of new entry.

As a final point on Figure 3, note that the lines shift downwards when there are additional firms of the other type. Hence the critical market sizes drop as there are more firms of the other type, reflecting the extent of strategic complementarities between both professions.

\section{$<$ Figure 3 $>$}

\footnotetext{
${ }^{23}$ A convex relationship would have been evidence that additional entry leads to intensified competition. To test the relationship between the critial market size and the number of firms more formally, we also computed Bresnahan and Reiss' (1991) per-firm entry threshold ratio's. We found that they are indeed not significantly different from one for both pharmacies and physicians. See Schaumans and Verboven (2006) for detailed results.
} 


\section{$5 \quad$ Policy reform towards pharmacies}

According to the public interest view, pharmacies receive high regulated markups in combination with tight geographic entry restrictions to ensure a sufficient coverage of pharmacies in the less attractive areas, without triggering excessive entry elsewhere. To evaluate whether this view has empirical support, it is necessary to assess the combined effects of both liberalizing entry and reducing the regulated markups.

Our counterfactual analysis essentially proceeds as follows. First, to account for entry liberalization, we adjust the maximum allowed number of pharmacies per municipality upwards by a factor $\Phi \geq 1$. Equivalently, this amounts to dividing the population threshold criteria set out in the establishment act by this factor $\Phi$. For example, $\Phi=1.1$ amounts to lowering the required number of inhabitants per pharmacy from 2,000 to 1,818. Second, to account for the pharmacies' reduced regulated markups, we adjust the net markups downwards by a factor $0 \leq \Delta \leq 1$. For example, $\Delta=0.75$ means that net markups drop to $75 \%$ of the original levels. We then use the parameter estimates of the entry model to make new entry predictions under alternative levels of $\Phi$ and $\Delta$. For $\Phi=1$ and $\Delta=1$, we obtain the status quo predictions of the current regime (same entry restrictions and same markups). If $\Phi$ is arbitrarily large, we obtain predictions when entry becomes completely free. The reader who is not interested in the details of our approach can skip section 5.1, and immediately go to the discussion of our findings in section 5.2.

\subsection{Approach}

We first discuss how to make entry predictions after entry liberalization without changing the pharmacies' regulated markups (alternative values of $\Phi$ keeping $\Delta=1$ ). For each market, we take 1,000 draws from the estimated bivariate normal distribution for the error terms $\varepsilon_{1}$ and $\varepsilon_{2}$. For each market and draw, we compute the maximum number of pharmacies and physicians that can profitably enter, subject to the considered entry restriction $(\Phi)$. We then average these numbers over the 1,000 draws to obtain the expected number of pharmacies and physicians per market. There is one issue stemming from the fact that the establishment act restricts the maximum allowed number of pharmacies at the municipality level and not at the market (town) level, which is the unit of our analysis. For example, entry liberalization may allow for one additional pharmacy in a certain municipality, but this does not stipulate in which market within the municipality the additional pharmacy may enter. In our counterfactuals we will assume that the extra allowed pharmacy will enter (if profitable) in the market where the profits are highest. More generally, if entry liberalization allows for one or more than one additional pharmacies in a municipality, we assume that 
they enter (as long as profitable) in the markets where profits are the highest. ${ }^{24}$

We also make entry predictions after a reduction in the pharmacies' regulated markups (in combination with entry liberalization). More precisely, we look at a drop in the net markups $\mu$ by a factor $\Delta$, where $0 \leq \Delta \leq 1$, i.e. a drop from $\mu$ to $\mu \Delta$. To model the effects of such a markup drop, we require a more precise economic interpretation of the pharmacies' payoffs $\pi_{1}^{*}\left(N_{1}, N_{2}\right)$, as specified earlier by (8). In a direct interpretation the payoffs are simply profits. We adopt an alternative interpretation here. Define a pharmacy's profits as $\Pi_{1}^{*}\left(N_{1}, N_{2}\right)=S \mu R\left(N_{1}, N_{2}\right) \exp \left(-\varepsilon_{1}\right)-F_{1}\left(N_{1}, N_{2}\right)$, where $S$ is the number of consumers (defined before), $R\left(N_{1}, N_{2}\right)$ is revenues per consumer, $F_{1}\left(N_{1}, N_{2}\right)$ is fixed costs, and $\varepsilon_{1}$ is a multiplicative error term capturing unobserved variable profits or fixed costs. This assumes that the variable profits (first term) are proportional to the number of consumers $S$, and that the net markup $\mu$ is constant and uniform across markets. Both assumptions are reasonable for pharmacies. ${ }^{25}$ Pharmacies then enter if and only if $\Pi_{1}^{*}\left(N_{1}, N_{2}\right) \geq 0$, or equivalently if and only if

$$
\pi_{1}^{*}\left(N_{1}, N_{2}\right)=\ln (S)+\ln (\mu)+\ln \left(R\left(N_{1}, N_{2}\right) / F_{1}\left(N_{1}, N_{2}\right)\right)-\varepsilon_{1} \geq 0 .
$$

Hence, the payoffs $\pi_{1}^{*}\left(N_{1}, N_{2}\right)$ receive the interpretation of the logarithm of the ratio of variable profits over fixed costs, and all included variables should be interpreted as affecting this ratio. ${ }^{26}$ Specifying $\ln \left(R\left(N_{1}, N_{2}\right) / F_{1}\left(N_{1}, N_{2}\right)\right)=X \bar{\beta}_{1}-\bar{\alpha}_{1}^{j}+\bar{\gamma}_{1}^{k} / j$ and substituting into (10), we essentially obtain our earlier payoff specification (8). The main difference is that the coefficient on $\ln (S)$ is now restricted to 1 (because variable profits are proportional with $S$ ). Consequently, the standard deviation of $\varepsilon_{1}$, i.e. $\sigma_{1}$, becomes identified: we can interpret the earlier estimated population coefficient $\lambda_{1}$ as $1 / \sigma_{1}$. Furthermore, we can interpret the earlier estimated intercept $\beta_{1}^{0}$ as $\left(\bar{\beta}_{1}^{0}+\ln (\mu)\right) / \sigma_{1}$, i.e. as containing the net markup $\mu$. We can therefore model a lowering of the pharmacies' net markups from $\mu$ to $\mu \Delta$ as a reduction in the intercept from $\beta_{1}^{0}$ to $\beta_{1}^{0}+\lambda_{1} \ln (\Delta)$. Using this new intercept, we can proceed as before to make entry predictions for alternative values of $\Phi$ and $\Delta$.

Our counterfactuals consider a relative reduction in the net markup from $\mu$ to $\Delta \mu$. To retrieve the absolute reduction in the gross markup $\nu$ (currently regulated at $23 \%$ ), we would

\footnotetext{
${ }^{24}$ As a robustness check, we also did our counterfactuals under the assumption that the establishment act applies at the market (town) level rather than at the municipality level. This is a simpler but less realistic approach, yet the counterfactual results are similar. See Schaumans and Verboven (2006).

${ }^{25}$ Gross markups are regulated at a uniform rate and our empirical results showed no evidence of non-price competition. Furthermore, there are no scale economies in distribution to pharmacies, apart from the fixed costs of setting up a pharmacy.

${ }^{26}$ This is similar to Genesove (2001), and it differs from e.g. Bresnahan and Reiss (1991) who directly interpret $\pi_{1}^{*}\left(N_{1}, N_{2}\right)$ as profits (so that the error term has the interpretation of an additive profit component).
} 
require additional information on the variable retail costs other than the wholesale costs. A reasonable starting point is to assume that the other variable retail costs are zero, so that $\mu=\nu \cdot{ }^{27}$ The absolute reduction in the gross regulated markups is then simply $\nu(\Delta-1)$, where $\nu=23 \%$. As a robustness check, we will also consider the possibility that there are other variable retail costs, so $\mu<\nu$. It can be verified that the implied absolute gross markup reduction is then given by $((1-\nu) /(1-\mu)) \mu(\Delta-1)$. In this formula, we again have $\nu=23 \%$, and we set $\mu=\nu-10 \%=13 \%$, i.e. we assume that other variable retail costs amount to $10 \%$.

\section{$5.2 \quad$ Findings}

Table 4 summarizes the entry predictions under alternative regulatory policies towards entry and markups of pharmacies. The results are based on the estimates of the general model with strategic complements (third part of Table 3). We obtain similar results from the model without strategic complements (second column of Table 3 with $\gamma_{i}^{k}=0$ ), except that there are of course no indirect effects on the physicians in that case. Table 4 compares three entry regimes: the status quo entry regulation (Panel A with $\Phi=1$ ), "partial" entry deregulation where the maximum allowed number of pharmacies in each market is doubled (Panel B with $\Phi=2$ ), and a full free entry situation (Panel $\mathrm{C}$ with $\Phi$ large). We also consider four possible net markups (four different columns): no change in the markups $(\Delta=1)$, relative drops to $75 \%$ and $50 \%$ of the original levels $(\Delta=0.75$ and $\Delta=0.5)$ and a non-uniform markup drop to $\Delta=0.4$ for large markets (above-average population size) and $\Delta=0.6$ for small markets. To illustrate, the relative net markup reduction of $\Delta=0.5$ amounts to an absolute gross markup reductions from $23 \%$ to $11.5 \%$ if there are no other variable retail costs than wholesale costs, and to $5.8 \%$ if other variable retail costs amount to $10 \%$.

The first column of Table 4 shows the predictions under the three entry regimes, assuming no changes in markups. ${ }^{28}$ The total number of pharmacies (the sum across all markets) is predicted to increase from 1,515 to 2,330 (or $+54 \%$ ) under partial entry deregulation, and to 4,140 (or $+173 \%$ ) under full free entry. The current entry restrictions, which Table 1 documented to be binding in more than $80 \%$ of the markets, are thus also economically important. Furthermore, the first column shows that entry deregulation would also have indirect effects on the physicians. Their number would increase from 4,371 to 4,563 (or

\footnotetext{
${ }^{27}$ The pharmacies' most important other retail costs are labor costs. It is not unreasonable to treat these as fixed, since time spent on servicing patients is essentially fixed during opening hours (in contrast to physicians who spend a variable amount of their time on servicing patients).

${ }^{28}$ The model predicts the status quo outcomes reasonably well. For example, Table 1 showed that there are 246 (154) markets without any pharmacy (physician), whereas the model predicts that there are 242 (152) such markets.
} 
$+4 \%$ ) under partial entry deregulation, and to 4,683 (or $+7 \%$ ) under full free entry. These effects stem from our earlier finding that the entry decisions of pharmacies and physicians are strategic complements. Finally, the first column shows how the geographic coverage of health care services changes after entry deregulation. For example, full free entry would drastically reduce the number of markets without a pharmacy from 242 to 145 . This large reduction stems from the fact that the current entry restrictions were actually binding for 199 of the uncovered pharmacy markets, as documented earlier in Table $1 .^{29}$

Policy makers such as the O.E.C.D. have warned against too simple conclusions regarding the effects of liberalizing entry regulations. According to the public interest view the high regulated markups and tight entry restrictions ensure a sufficient coverage of pharmacies in the less attractive areas, without triggering excessive entry elsewhere. To evaluate this view, it is therefore important to look at the combined effects of lowering markups and liberalizing entry restrictions. The second and third columns of Table 4 show the effects from uniformly scaling down markups by a factor $\Delta=0.75$ or $\Delta=0.5$. If this is done without liberalizing the entry restrictions (panel A), the total number of pharmacies evidently drops from 1,515 to respectively 1,437 and 1,273. Geographic coverage would also decrease: the number markets without pharmacies increases from 242 to respectively 254 and 286. In contrast, if the markup reductions are combined with entry liberalization (panels B and C), the number of pharmacies would no longer decrease. For example, the number of pharmacies increases from 1,515 to 2,176 if a $50 \%$ net markup reduction is combined with full free entry. ${ }^{30}$ Furthermore, reduced geographic coverage is no longer necessarily a source of concern under a combined policy. For a markup reduction of $\Delta=0.75$, the total number of markets without any pharmacy actually drops from 242 to 207 under partial entry liberalization and to 180 under full free entry. For a larger markup reduction of $\Delta=0.5$, geographic coverage slightly worsens from 242 to 255 unserved markets under partial deregulation, but it remains unchanged at 242 unserved markets under full free entry (panel B third column).

To avoid that geographic coverage goes down after a large markup reduction, the government could use additional instruments. For example, it could favour pharmacies in the smaller markets through non-uniform markup regulation. The fourth column of Table 4 shows the effects from scaling down the markups in a non-uniform way, by a factor $\Delta=0.4$ in markets with an above-average population size and by $\Delta=0.6$ in markets with belowaverage population size. Such a policy indeed helps to improve geographic coverage. For

\footnotetext{
${ }^{29}$ Recall that this is due to the fact that the entry restrictions apply at the larger municipality level rather than at the market level. Hence, the constraint may be binding in an uncovered market if there are already too many pharmacies in other markets of the same municipality.

${ }^{30}$ The indirect effects on physicians are small but the availability of physicians usually slightly increases when entry liberalization is combined with a lowering of the markups.
} 
example, when the non-uniform markup drop is combined with full free entry the number of markets without a pharmacy goes down to 227 .

In sum, the public interest motivation for combining high markups and tight entry restrictions as a way to ensure geographic coverage does not find empirical support. The government may in fact ensure a higher geographic coverage by simultaneously liberalizing the entry restrictions and lowering the regulated markups (either uniformly or in a non-uniform way by favouring the pharmacies in the smaller markets).

$$
<\text { Table } 4>
$$

To further explore this, it would be interesting to know the optimal number of firms and the required policies to ensure this. A complete welfare analysis is not possible within our empirical framework. However, we can address a related question that sheds partial light on this issue. We ask how the entry restrictions can be liberalized (through $\Phi$ ) and the net markup can be reduced (through $\Delta$ ) in such a way that the total number of pharmacies in the country remains constant at the current predicted level of 1,515 . We then also compute the associated reductions in the absolute gross markups and the number of markets without any pharmacy. By keeping the total number of pharmacies constant, we maintain the current level of duplicated fixed costs in the country, and look at the effects on the pharmacies' rents and local geographic coverage. ${ }^{31}$

Table 5 shows the results from this policy experiment. The first and second columns show the combinations of entry restrictions and net markups such that the total number of pharmacies in the country remains constant at the predicted status quo level. To illustrate, multiplying the maximum allowed number of pharmacies to $\Phi=1.75$ requires a drop in the net markups to $\Delta=47 \%$ of the original levels. In general, as the entry restrictions become more liberalized (higher $\Phi$ ), the net markups should drop by more (lower $\Delta$ ) to keep the total number of pharmacies in the country constant. With full free entry, the net markups can drop to $34.6 \%$ of the original levels. To know how these changes translate into absolute reductions of the regulated gross markups, the third and fourth columns consider the cases with no other variable retail costs than wholesale costs $(\mu=\nu)$, and with other variable retail costs amounting to $10 \%(\mu=\nu-10 \%)$. Gross markups can drop by a large amount, even if there are other variable retail costs. For example, if entry would become fully free, the regulated gross markups can decrease by between $7.5 \%$ and $15 \%$ in absolute terms without changing the total number of pharmacies. Note however that in this policy experiment the number of markets without a pharmacy would increase. Hence, a combined entry/markup

\footnotetext{
${ }^{31}$ Of course, if the current number of pharmacies is actually too high, it would be even better to further reduce the markups for a given entry policy (and vice versa if the current number is too low).
} 
policy such that the total number of pharmacies is kept constant reduces geographic coverage to some extent. To preserve geographic coverage, a relatively moderate entry liberalization policy may therefore be adequate. For example, setting $\Phi=1.5$ already implies a substantial markup drop of $\Delta=0.533$ to keep the total number of pharmacies constant, and raises the number of unserved markets to only 259. Furthermore, a non-uniform markup drop may be introduced to improve geographic coverage. For example, $\Phi=1.5$ can be combined with a markup drop of $\Delta=0.433$ in markets with above-average population size and $\Delta=0.791$ in markets with below-average population size. This would also keep the total number of pharmacies constant, and at the same time improve geographic coverage to only 235 unserved markets. ${ }^{32}$

Overall, these policy counterfactuals illustrate that the government can generate potentially large budgetary savings from liberalizing entry without reducing the availability of supply.

$$
<\text { Table } 5>
$$

\section{Conclusions}

We have studied the role of professional regulation in health care professions. We have looked at geographic entry restrictions on Belgian pharmacies, as combined with high regulated markups. We consider both the direct impact of the regulations on the pharmacies, and the indirect impact on the physicians. We find that the geographic entry restrictions have substantially reduced the number of pharmacies, and have also reduced the number of physicians (since the professions' entry decisions are strategic complements). Given that the markups are regulated at a distortionary high level, these entry restrictions may in principle be socially desirable. We have therefore also looked at the combined effects of the entry restrictions and regulated markups. Our results shows that a suitably designed policy that simultaneously liberalizes the entry restrictions and lowers the regulated markups would lead to substantial shifts in rents from pharmacies to consumers (tax payers) without necessarily reducing the availability of supply.

The next question is whether these findings are sufficiently strong to warrant conclusions to liberalize the professions. The answer depends on the nature of the current rents to pharmacies. If they are simply a transfer, liberalization would only have distributional effects. Two arguments may, however, be provided as to why the pharmacies' current rents

\footnotetext{
${ }^{32}$ More generally, we considered policies of alternative $\Phi$ and non-uniform markup drops such that the total number of pharmacies remains constant. The results from these counterfactuals are available on request. They show that geographic coverage improves if the markup drop is sufficiently non-uniform.
} 
may be socially wasteful. First, their rents are to the detriment of consumers as taxpayers. This will be inefficient to the extent that the required taxes create distortions elsewhere in the economy. Second, the rents themselves may have been dissipated in the form of wasteful investments. Along the lines of Posner's (1975) argument, pharmacies and their organization would need to engage in inefficient lobbying and related activities to maintain the rents.

We hope that our analysis will stimulate additional research, which is highly relevant from a policy perspective. In the U.S., efforts have already been done to liberalize entry and conduct regulation, but exceptions such as taxicabs remain. In Europe, policy makers have only recently opened the debate to reform the liberal professions, and to make their practices in line with competition policy. The European Commission recently published a large report by Paterson et al. (2003) documenting the country-specific regulations of several professions, such as accountants, engineers, lawyers, pharmacies, and notaries. As another example, the U.K.'s Office of Fair Trading (2003) published a report on reforming the pharmacies. Our analysis shows how these policy issues can be addressed by suitably adapting empirical models of free entry to account for entry restrictions and other relevant factors.

\section{References}

Athey, S. and Stern, S., "An Empirical Framework for Testing Theories about Complementarity in Organizational Design". NBER Working Paper 6600 (2003).

Berry, S.T., "Estimation of a Model of Entry in the Airline Industry." Econometrica, Vol. 60 (1992), pp. 889-917.

Berry, S.T. and Waldfogel, J., "Free Entry and Social Inefficiency in Radio Broadcasting." RAND Journal of Economics, Vol. 30 (1999), pp. 397-420.

Bresnahan, T.F. and Reiss, P.C., "Entry in Monopoly Markets." Review of Economic Studies, Vol. 57 (1990), pp. 531-53.

Bresnahan, T.F. and Reiss, P.C., "Empirical Models of Discrete Games." Journal of Econometrics, Vol. 48 (1991), pp. 57-81.

Bresnahan, T.F. and Reiss, P.C., "Entry and Competition in Concentrated Markets." Journal of Political Economy, Vol. 99 (1991), pp. 977-1009.

Ciliberto, F. and Tamer, E., "Market Structure and Equilibria in Airline Markets." Working paper (2004).

Cohen, A. and Mazzeo, M., "Investment Strategies and Market Structure: An Empirical Analysis of Bank Branching Decisions." Working Paper (2005).

de Bruyn, J.P.G.M., "De apotheek in België." Pharmaceutisch Weekblad, Vol. 129 (1994), pp. 608-611. 
De Bruyn, K., "Ke(r)ngetallen 2005". Apothekersblad, Vol. 4 (2006).

Davis, P., "Estimation of Quantity Games in the Presence of Indivisibilities and Heterogeneous Firms." Journal of Econometrics, Vol. 134 (2006), pp. 187214.

Dranove, D. and Satterthwaite M.A., "The Industrial Organization of Health Care Markets." Handbook of Health Economics (2000), Edited by A. J. Culyer and J. P. Newhouse.

Genesove, D., "Why Are There So Few (and Fewer and Fewer) Two-Newspaper Towns?" Working Paper (2001).

Hsieh, C.-T. and Moretti, E., "Can Free Entry Be Socially Inefficient? Fixed Commissions and Social Waste in the Real Estate Industry.", Journal of Political Economy, Vol. 111 (2003), pp. 1076-1122.

Lafontaine, F. and Slade, M., "Exclusive Contracts and Vertical Restraints: Empirical Evidence and Public Policy." Forthcoming in Handbook of Antitrust Economics, Paolo Buccirossi (ed.) Cambridge: MIT Press.

Mankiw, N.G. and Whinston, M.D., "Free Entry and Social Inefficiency." RAND Journal of Economics, Vol. 17 (1986), pp. 48-58.

Mazzeo, M.J., "Product Choice and Oligopoly Market Structure." RAND Journal of Economics, Vol 33 (2002), pp. 221-242.

Miravete, E.J. and Pernías, J.C., "Innovation Complementarity and Scale of Production". Journal of Industrial Economics, Vol. 54 (2006), pp. 1-29.

Office of Fair Trading (OFT), "The control of entry regulations and retail pharmacy services in the UK." Report Office of Fair Trading (2003), OFT609.

O.E.C.D., "Competition and Regulation Issues in the Pharmaceutical Industry." OECD Economic Studies (2000), DAFFE/CLP(2000)29.

Pakes, A., Ostrovsky, M. and Berry, S., "Simple Estimators for the Parameters of Discrete Dynamic Games." Working Paper (2005).

Paterson, I., Fink, M. and Ogus, A., "Economic impact of regulation in the field of liberal professions in different Member States." European Commission, Institute for Advances Studies of Vienna (2003).

Philipsen, N.J., "Regulation of and by Pharmacists in the Netherlands and Belgium: an Economic Approach." Dissertation, Universiteit Maastricht (2003).

Posner, R., "The Social Costs of Monopoly and Regulation." Journal of Political Economy, Vol. 83 (1975), pp. 807-827.

Schaumans, C., and F. Verboven, "Entry and Regulation: Evidence from Health Care Professions, C.E.P.R. Discussion Paper No. 5482 (2006).

Seim, K., "An Empirical Model of Firm Entry with Endogenous Product-Type Choices." RAND Journal of Economics, forthcoming (2005). 
Sweeting, A., "Coordination Games, Multiple Equilibria and the Timing of Radio Commercials", working paper.

Vives, X., "Complementarities and Games: New Developments", Journal of Economic Literature, 43 (2005), 437-479.

Wetenschappelijk Instituut Volksgezondheid (WIV), "Gezondheidsenquête, België 2001." Nationaal Instituut voor de Statistiek (2002), IPH/EPI REPORTS Nr. 2002-22.

Wise, M., "Competition and Regulatory Reforms." OECD Journal of Competition Law and Policy, Vol. 3 (2001), pp. 60-109. 


\section{Appendix}

This Appendix first characterizes the multiplicity of Nash equilibria outcomes when the entry decisions of firms of different types are strategic complements.

If the entry decisions by firms of different types are strategic complements, i.e. Assumption 2(a) holds with strict inequality, then $\left(n_{1}, n_{2}\right)$ may show multiplicity with other equilibrium outcomes of the general form $\left(n_{1}+m_{1}, n_{2}+m_{2}\right)$. The three Claims below show that the multiplicity can be characterized in a simple way if Assumptions 1 and 2 are satisfied. Taken together, these Claims imply that the areas of $\varepsilon$ for which $\left(n_{1}, n_{2}\right)$ shows multiplicity with any other Nash equilibrium outcome are simply given by the areas of overlap with $\left(n_{1}+1, n_{2}+1\right)$ and $\left(n_{1}-1, n_{2}-1\right)$.

Define $A\left(n_{1}, n_{2}\right)$ as the set of $\varepsilon$ for which $\left(n_{1}, n_{2}\right)$ is a Nash equilibrium outcome, as given by the conditions (2) in the text. Furthermore, define $B\left(n_{1}, n_{2}, m_{1}, m_{2}\right)$ as the set of $\varepsilon$ for which both $\left(n_{1}, n_{2}\right)$ and $\left(n_{1}+m_{1}, n_{2}+m_{2}\right)$ are a Nash equilibrium, i.e. $B\left(n_{1}, n_{2}, m_{1}, m_{2}\right)=$ $A\left(n_{1}, n_{2}\right) \cap A\left(n_{1}+m_{1}, n_{2}+m_{2}\right)$, where $m_{1}$ and $m_{2}$ are positive or negative integers.

Claim 1. $B\left(n_{1}, n_{2}, m_{1}, m_{2}\right)$ is empty if $m_{1} \neq m_{2}$. I.e., $\left(n_{1}, n_{2}\right)$ may only show multiplicity with Nash equilibrium outcomes of the form $\left(n_{1}+m, n_{2}+m\right)$, where $m$ is a positive or a negative integer.

Proof: Suppose to the contrary that there are also equilibrium outcomes of the form $\left(n_{1}+\right.$ $\left.m_{1}, n_{2}+m_{2}\right)$, where $m_{1} \neq m_{2}$. There are several cases:

(i) If $m_{1}>0$ and $m_{2}<0$, then $\varepsilon_{1} \leq \pi_{1}\left(n_{1}+m_{1}, n_{2}+m_{2}\right) \leq \pi_{1}\left(n_{1}+m_{1}, n_{2}\right) \leq \pi_{1}\left(n_{1}+1, n_{2}\right)$, by the conditions for $\left(n_{1}+m_{1}, n_{2}+m_{2}\right)$ to be a Nash equilibrium, by Assumption 2(a) and by Assumption 1.

(ii) If $m_{1}>0$ and $m_{2}>0$, and $m_{1}>m_{2}$, then $\varepsilon_{1} \leq \pi_{1}\left(n_{1}+m_{1}, n_{2}+m_{2}\right)<\pi_{1}\left(n_{1}+\right.$ $\left.m_{1}-m_{2}, n_{2}\right) \leq \pi_{1}\left(n_{1}+1, n_{2}\right)$, by the conditions for $\left(n_{1}+m_{1}, n_{2}+m_{2}\right)$ to be a Nash equilibrium, by Assumption 2(b), and by Assumption 1.

(iii) If $m_{1}>0$ and $m_{2}>0$, and $m_{1}<m_{2}$, then $\varepsilon_{2} \leq \pi_{2}\left(n_{1}+m_{1}, n_{2}+m_{2}\right)<\pi_{2}\left(n_{1}, n_{2}+\right.$ $\left.m_{2}-m_{1}\right) \leq \pi_{2}\left(n_{1}, n_{2}+1\right)$, by the conditions for $\left(n_{1}+m_{1}, n_{2}+m_{2}\right)$ to be a Nash equilibrium, by Assumption 2(b), and by Assumption 1 .

(iv) If $m_{1}<0$ and $m_{2}>0$, then $\varepsilon_{2} \leq \pi_{2}\left(n_{1}+m_{1}, n_{2}+m_{2}\right) \leq \pi_{2}\left(n_{1}, n_{2}+m_{2}\right) \leq \pi_{2}\left(n_{1}, n_{2}+1\right)$, by the condition for $\left(n_{1}+m_{1}, n_{2}+m_{2}\right)$ to be Nash, by Assumption 2(a) and by Assumption 1. 
(v) If $m_{1}<0$ and $m_{2}<0$, and $m_{1}>m_{2}$, then $\pi_{2}\left(n_{1}, n_{2}\right) \leq \pi_{2}\left(n_{1}, n_{2}+m_{2}-m_{1}+1\right)<$ $\pi_{2}\left(n_{1}+m_{1}, n_{2}+m_{2}+1\right)<\varepsilon_{2}$, by Assumption 1, by Assumption 2(b), and by condition for $\left(n_{1}+m_{1}, n_{2}+m_{2}\right)$ to be Nash.

(vi) If $m_{1}<0$ and $m_{2}<0$, and $m_{1}<m_{2}$, then $\pi_{1}\left(n_{1}, n_{2}\right) \leq \pi_{1}\left(n_{1}+m_{1}-m_{2}+1, n_{2}\right)<$ $\pi_{1}\left(n_{1}+m_{1}+1, n_{2}+m_{2}\right)<\varepsilon_{1}$, by Assumption 1, by Assumption 2(b), and by the condition for $\left(n_{1}+m_{1}, n_{2}+m_{2}\right)$ to be Nash.

In all cases we have obtained a contradiction with the conditions $(2)$ for $\left(n_{1}, n_{2}\right)$ to be a Nash equilibrium outcome.

Claim 2. $B\left(n_{1}, n_{2}, 1,1\right)$ and $B\left(n_{1}, n_{2},-1,-1\right)$ are not empty. I.e., $\left(n_{1}, n_{2}\right)$ shows multiplicity with $\left(n_{1}+1, n_{2}+1\right)$ and $\left(n_{1}-1, n_{2}-1\right)$.

Proof: The set $B\left(n_{1}, n_{2}, 1,1\right)$ is given by the conditions (3) in the text. Since we assume that Assumption 2(a) holds with strict inequality, this set is not empty. A similar reasoning applies to the set $B\left(n_{1}, n_{2},-1,-1\right)$.

Claim 3. $B\left(n_{1}, n_{2}, m, m\right) \subset B\left(n_{1}, n_{2}, 1,1\right)$ if $m>1$, and $B\left(n_{1}, n_{2}, m, m\right) \subset B\left(n_{1}, n_{2},-1,-1\right)$ if $m<-1$. I.e., while $\left(n_{1}, n_{2}\right)$ may also show multiplicity with $\left(n_{1}+m, n_{2}+m\right)$ for $m>1$ or $m<1$, the areas of multiplicity are a subset of those with $\left(n_{1}+1, n_{2}+1\right)$ and $\left(n_{1}-1, n_{2}-1\right)$.

Proof: The set $B\left(n_{1}, n_{2}, m, m\right)$ is given by:

$$
\begin{aligned}
& \pi_{1}\left(n_{1}+1, n_{2}\right) \leq \varepsilon_{1} \leq \pi_{1}\left(n_{1}+m, n_{2}+m\right) \\
& \pi_{2}\left(n_{1}, n_{2}+1\right) \leq \varepsilon_{2} \leq \pi_{2}\left(n_{1}+m, n_{2}+m\right),
\end{aligned}
$$

which may or may not be empty. Since the left-hand-side in (11) is the same as in (3), and the right hand side in (11) is less than in (3) by Assumption 2(b), we have $B\left(n_{1}, n_{2}, m, m\right) \subset$ $B\left(n_{1}, n_{2}, 1,1\right)$ if $m>1$. A similar reasoning applies to show that the set $B\left(n_{1}, n_{2}, m, m\right) \subset$ $B\left(n_{1}, n_{2},-1,-1\right)$ if $m<1$. 
Table 1. Observed market configurations*

\begin{tabular}{|c|c|c|c|c|c|c|c|c|c|}
\hline & \multicolumn{7}{|c|}{ number of pharmacies } & \multirow[t]{2}{*}{ Total } \\
\hline & & 0 & 1 & 2 & 3 & 4 & 5 & $6+$ & \\
\hline \multirow{12}{*}{$\begin{array}{l}\text { number of } \\
\text { physicians }\end{array}$} & 0 & 142 & 11 & 1 & 0 & 0 & 0 & 0 & 154 \\
\hline & 1 & 62 & 36 & 2 & 0 & 0 & 0 & 0 & 100 \\
\hline & 2 & 27 & 58 & 3 & 0 & 1 & 0 & 0 & 89 \\
\hline & 3 & 6 & 38 & 16 & 3 & 0 & 0 & 0 & 63 \\
\hline & 4 & 8 & 35 & 31 & 4 & 0 & 0 & 0 & 78 \\
\hline & 5 & 0 & 13 & 20 & 5 & 1 & 1 & 0 & 40 \\
\hline & 6 & 0 & 12 & 22 & 15 & 2 & 1 & 0 & 52 \\
\hline & 7 & 0 & 5 & 18 & 23 & 2 & 1 & 0 & 49 \\
\hline & 8 & 0 & 6 & 7 & 12 & 12 & 1 & 0 & 38 \\
\hline & 9 & 0 & 3 & 9 & 11 & 6 & 2 & 0 & 31 \\
\hline & 10 & 0 & 0 & 9 & 9 & 11 & 4 & 3 & 36 \\
\hline & $11+$ & 1 & 2 & 8 & 20 & 35 & 25 & 26 & 117 \\
\hline \multirow{3}{*}{\multicolumn{2}{|c|}{$\begin{array}{l}\text { Total } \\
\text { restricted entry } \\
\% \text { of total }\end{array}$}} & 246 & 219 & 146 & 102 & 70 & 35 & 29 & 847 \\
\hline & & 199 & 179 & 109 & 85 & 61 & 35 & 29 & 697 \\
\hline & & 80,9 & 81,7 & 74,7 & 83,3 & 87,1 & 100,0 & 100,0 & 82,3 \\
\hline
\end{tabular}

* Source: RIZIV as discussed in the text. 
Table 2. Summary statistics*

\begin{tabular}{l|l|cc}
\hline Variable & Description & mean & std. dev. \\
\hline \# pharmacies & Number of pharmacies & 1.76 & 1.81 \\
\# physicians & Number of physicians & 4.93 & 4.62 \\
$\ln$ (population) & Logarithm of population & 7.91 & 1.13 \\
\% young & Fraction of population, 17 years or younger & 22.50 & 2.55 \\
\% old & Fraction of population, 65 years or older & 16.11 & 2.79 \\
$\%$ foreign & Fraction of population with foreign nationality & 4.27 & 5.67 \\
$\%$ unemployed & Unemployment rate & 5.61 & 2.80 \\
Flanders & Dummy variable, 1 for the region of Flanders & 0.39 & 0.49 \\
mean income & Mean income (in 10,000€) & 2.47 & 0.40 \\
\hline \hline
\end{tabular}

* 847 observations (markets in 2001). Source: RIZIV, NIS, Ecodata, and the RSZ as discussed in text. 
Table 3. Estimation results*

\begin{tabular}{|c|c|c|c|c|c|c|}
\hline & \multicolumn{4}{|c|}{ Bivariate ordered probit models } & \multirow{2}{*}{\multicolumn{2}{|c|}{$\begin{array}{l}\text { General model with } \\
\text { strategic complements }\end{array}$}} \\
\hline & \multicolumn{2}{|c|}{$\begin{array}{l}\text { No account for } \\
\text { entry restrictions }\end{array}$} & \multicolumn{2}{|c|}{$\begin{array}{c}\text { Account for } \\
\text { entry restrictions }\end{array}$} & & \\
\hline \multicolumn{7}{|c|}{ Pharmacies' payoff equation } \\
\hline constant & -19.05 & $(1.18)$ & -14.09 & $(3.40)$ & -13.54 & $(1.82)$ \\
\hline $\ln ($ population $)$ & 2.49 & $(0.06)$ & 1.95 & $(0.12)$ & 1.43 & $(0.13)$ \\
\hline$\%$ young & -0.31 & $(2.48)$ & 0.73 & $(9.18)$ & 0.22 & $(4.26)$ \\
\hline$\%$ old & 10.18 & $(2.43)$ & 19.00 & $(5.20)$ & 19.32 & $(3.54)$ \\
\hline$\%$ foreign & -1.03 & $(0.94)$ & -0.94 & $(0.96)$ & -1.00 & $(1.08)$ \\
\hline$\%$ unemployed & 9.20 & $(2.22)$ & 22.71 & $(4.85)$ & 23.06 & $(4.40)$ \\
\hline Flanders & -0.03 & $(0.14)$ & 0.13 & $(0.34)$ & 0.11 & $(0.25)$ \\
\hline income & -0.43 & $(0.14)$ & -0.35 & $(0.18)$ & -0.32 & $(0.19)$ \\
\hline$\alpha_{1}^{2}$ & 2.26 & $(0.11)$ & 1.50 & $(0.18)$ & 1.09 & $(0.23)$ \\
\hline$\alpha_{1}^{3}$ & 3.64 & $(0.13)$ & 2.56 & $(0.20)$ & 1.94 & $(0.30)$ \\
\hline$\alpha_{1}^{4}$ & 4.83 & $(0.15)$ & 3.14 & $(0.22)$ & 2.37 & $(0.35)$ \\
\hline$\gamma_{1}^{1}$ & - & & - & & 0.78 & $(0.29)$ \\
\hline \multicolumn{7}{|c|}{ Physicians' payoff equation } \\
\hline constant & -19.41 & $(0.94)$ & -19.28 & $(1.12)$ & -17.42 & $(0.98)$ \\
\hline $\ln$ (population) & 2.54 & $(0.07)$ & 2.53 & $(0.08)$ & 2.27 & $(0.07)$ \\
\hline$\%$ young & 3.45 & $(2.08)$ & 2.22 & $(2.25)$ & 2.02 & $(2.15)$ \\
\hline$\%$ old & 6.85 & $(1.84)$ & 6.81 & $(1.90)$ & 5.98 & $(1.89)$ \\
\hline$\%$ foreign & -3.61 & $(0.73)$ & -3.58 & $(0.69)$ & -3.43 & $(0.72)$ \\
\hline \% unemployed & 2.30 & $(1.83)$ & 2.29 & $(1.98)$ & 0.67 & $(1.89)$ \\
\hline Flanders & -0.65 & $(0.12)$ & -0.56 & $(0.13)$ & -0.58 & $(0.13)$ \\
\hline income & 0.32 & $(0.11)$ & 0.32 & $(0.12)$ & 0.37 & $(0.11)$ \\
\hline$\alpha_{2}^{2}$ & 1.30 & $(0.10)$ & 1.32 & $(0.10)$ & 1.23 & $(0.10)$ \\
\hline$\alpha_{2}^{3}$ & 2.34 & $(0.12)$ & 2.36 & $(0.12)$ & 2.27 & $(0.13)$ \\
\hline$\alpha_{2}^{4}$ & 2.99 & $(0.13)$ & 3.09 & $(0.13)$ & 2.91 & $(0.14)$ \\
\hline$\gamma_{2}^{1}$ & - & & - & & 0.16 & $(0.19)$ \\
\hline$\gamma_{2}^{2}$ & - & & - & & 2.01 & $(0.29)$ \\
\hline$\gamma_{2}^{3}$ & - & & - & & 3.89 & $(1.01)$ \\
\hline$\gamma_{2}^{4}$ & - & & - & & 5.99 & $(0.83)$ \\
\hline$\rho$ & 0.32 & $(0.03)$ & 0.05 & $(0.07)$ & -0.15 & $(0.09)$ \\
\hline Log Likelihood & -2 , & 5.6 & & 61.5 & & 40.6 \\
\hline \multicolumn{7}{|c|}{$\begin{array}{l}{ }^{*} \text { The number of observed markets is } 847 \text {. Standard errors are in parentheses. The other } \\
\text { estimated } \alpha_{2}^{j}, j=5 \cdots 21 \text { are not shown; constraints on the other } \alpha_{1}^{j}, j=5 \cdots 11 \text { and on } \\
\text { the other } \gamma_{i}^{k} \text { are discussed in the text. }\end{array}$} \\
\hline
\end{tabular}


Table 4. Summary entry predictions under alternative regulatory policies*

\begin{tabular}{|c|c|c|c|c|}
\hline & \multicolumn{4}{|c|}{ net markup change } \\
\hline & $\Delta=1$ & $\Delta=0.75$ & $\Delta=0.5$ & non-uniform \\
\hline \multicolumn{5}{|c|}{ Panel $A$ - no change in entry restrictions $(\Phi=1)$} \\
\hline number of pharmacies & 1515 & 1437 & 1273 & 1230 \\
\hline number of physicians & 4371 & 4337 & 4269 & 4264 \\
\hline number of markets without pharmacy & 242 & 254 & 286 & 279 \\
\hline number of markets without physician & 152 & 153 & 154 & 154 \\
\hline \multicolumn{5}{|c|}{ Panel $B$ - maximum number of pharmacies doubles $(\Phi=2)$} \\
\hline number of pharmacies & 2330 & 2067 & 1663 & 1595 \\
\hline number of physicians & 4563 & 4488 & 4362 & 4343 \\
\hline number of markets without pharmacy & 186 & 207 & 255 & 244 \\
\hline number of markets without physician & 144 & 146 & 150 & 150 \\
\hline \multicolumn{5}{|c|}{ Panel $C$ - full free entry in the pharmacy market ( $\Phi$ is large) } \\
\hline number of pharmacies & 4140 & 3191 & 2176 & 2088 \\
\hline number of physicians & 4683 & 4566 & 4399 & 4391 \\
\hline number of markets without pharmacy & 145 & 180 & 242 & 227 \\
\hline number of markets without physician & 127 & 136 & 145 & 143 \\
\hline \multicolumn{5}{|c|}{$\begin{array}{l}* \Phi=1 \text { refers to no change in entry restrictions, } \Phi=2 \text { to a doubling in the maximum number of } \\
\text { allowed pharmacies, and } \Phi \text { large to full free entry. Similarly, } \Delta=1 \text { refers to no change in the net } \\
\text { markups, } \Delta=0.75 \text { to a drop in the net markups to } 75 \% \text { of the original level } \Delta=0.5 \text { to a drop in } \\
\text { the net markups to } 50 \% \text { of the original level. Finally, the column 'non-uniform' refers to a large net } \\
\text { markup drop of } \Delta=0.4 \text { in markets with above-average population size and a smaller net markup } \\
\text { drop of } \Delta=0.6 \text { in markets with below-average population size. All entry predictions are based on } \\
\text { the parameter estimates of the general entry model with strategic complements (last column of Table } \\
3) .\end{array}$} \\
\hline
\end{tabular}


Table 5. Entry restrictions, markups and geographic coverage keeping the total number of pharmacies constant*

\begin{tabular}{c|c|cc|c}
\hline degree of entry & net markup drop & \multicolumn{2}{|c|}{ absolute gross markup drop } & number of markets \\
\cline { 3 - 4 } restriction $\Phi$ & by factor $\Delta$ & $\mu=\nu$ & $\mu=\nu-10 \%$ & without pharmacy \\
\hline 1 & 1.000 & $0 \%$ & $0 \%$ & 242 \\
1.25 & 0.664 & $-7.7 \%$ & $-3.9 \%$ & 250 \\
1.5 & 0.532 & $-10,8 \%$ & $-5.4 \%$ & 259 \\
1.75 & 0.470 & $-12.2 \%$ & $-6.1 \%$ & 269 \\
2 & 0.432 & $-13.0 \%$ & $-6.5 \%$ & 277 \\
2.25 & 0.411 & $-13.6 \%$ & $-6.8 \%$ & 282 \\
2.5 & 0.395 & $-13.9 \%$ & $-7.0 \%$ & 287 \\
large & 0.346 & $-15.0 \%$ & $-7.5 \%$ & 309 \\
\hline \hline
\end{tabular}

${ }^{*}$ For each considered $\Phi$ (first column), the relative net markup drop $\Delta$ is computed (second column) such that the total number of pharmacies remains constant at the predicted status quo level of 1,515 . The third and fourth column show the absolute gross markup drops corresponding to the relative net markup drop $\Delta$, assuming that retail costs other than wholesale costs amount to respectively $0 \%$ (so that $\mu=\nu$ ) and $10 \%$ (so that $\mu=\nu-10 \%$ ). The fifth column shows the corresponding number of markets without pharmacy. 
Figure 1. Nash equilibria with strategic complements

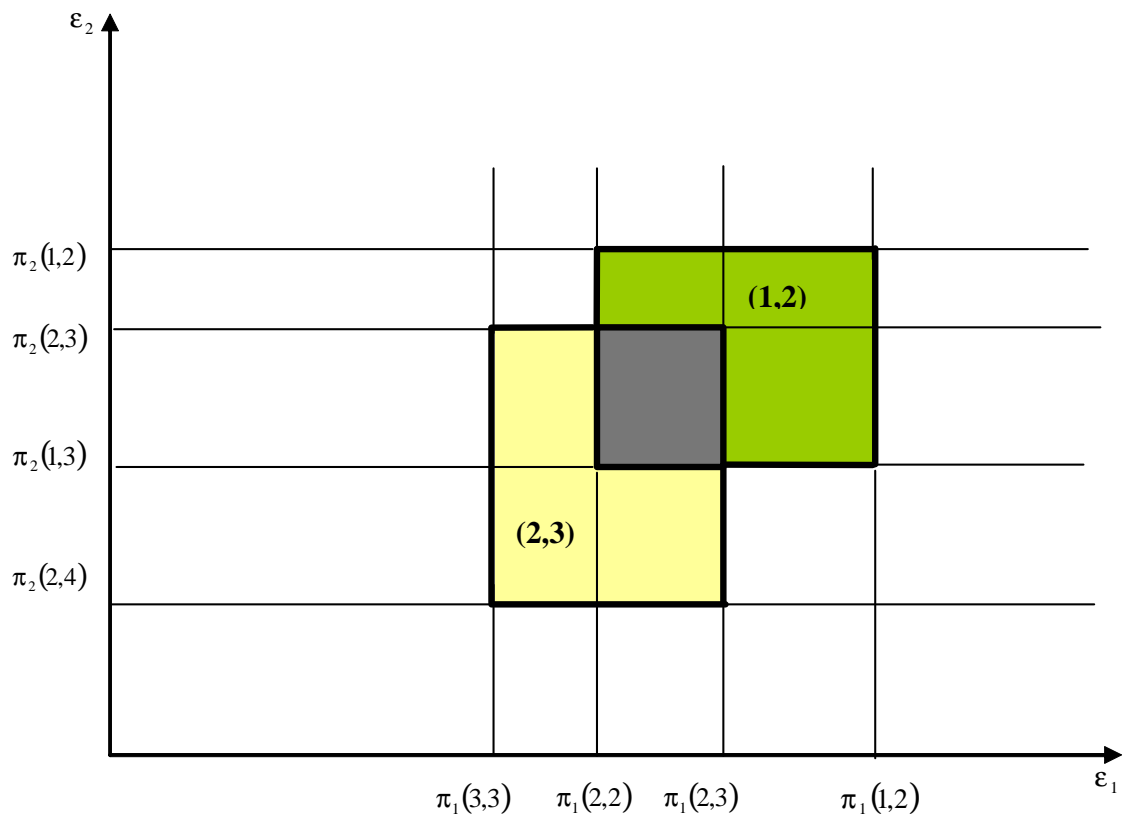


Figure 2. Nash equilibria - strong strategic complementarities

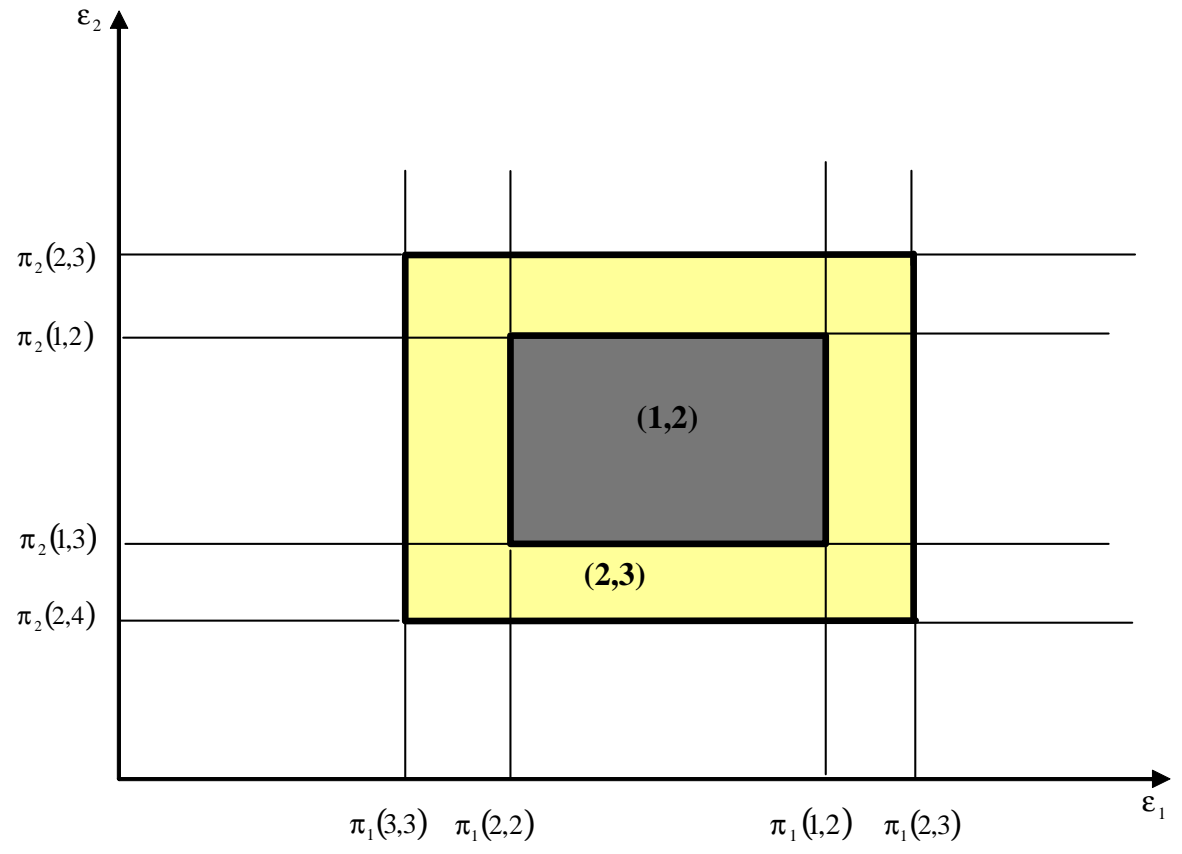


Figure 3. Entry thresholds of pharmacies and physicians

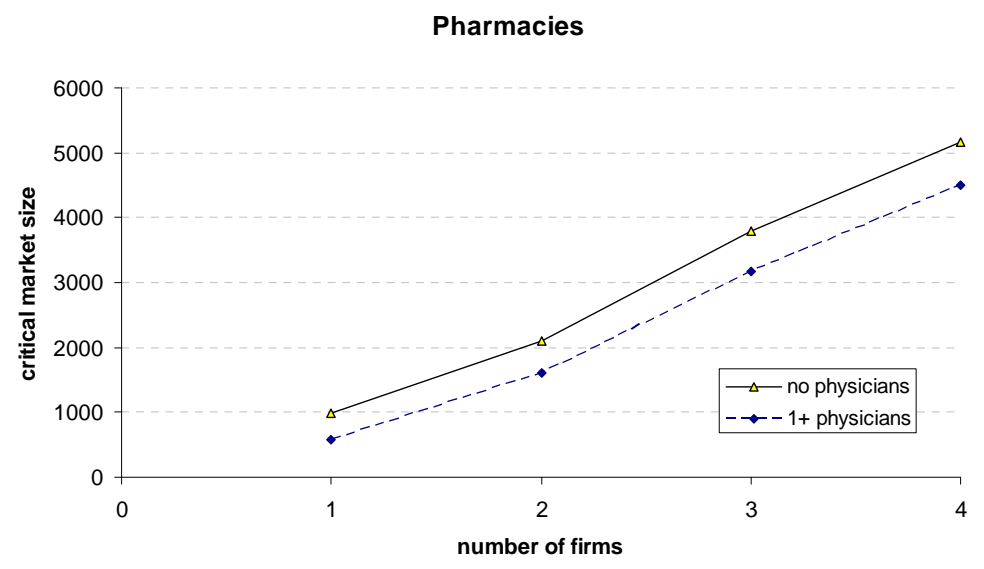

Physicians

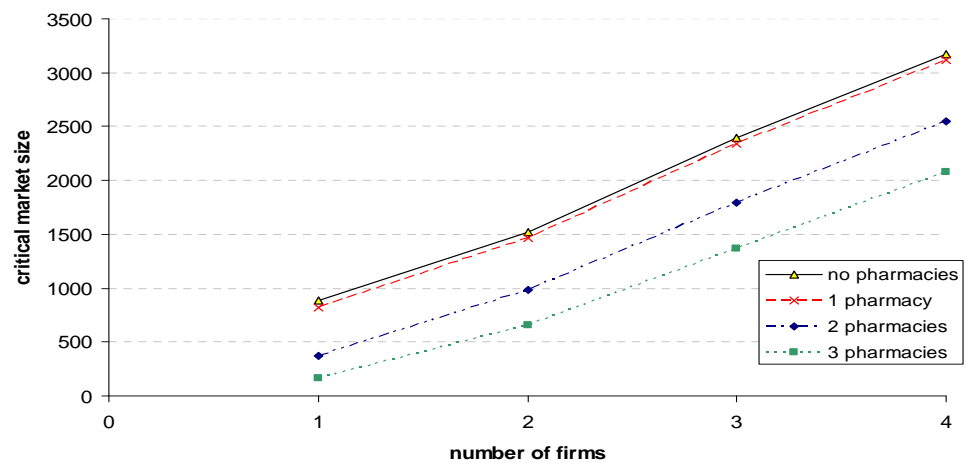

